Preprint: Nupur Bihari, Smruti Prasad Dash, Karankumar C. Dhankani, Joshua M. Pearce. 3-D printable open source dual axis gimbal system for optoelectronic measurements. Mechatronics 56, 175-187 (2018). DOI: https://doi.org/10.1016/j.mechatronics.2018.07.005

\title{
3-D Printable Open Source Dual Axis Gimbal System for Optoelectronic Measurements
}

Nupur Bihari, ${ }^{1}$ Smruti Prasad Dash, ${ }^{2}$ Karankumar C. Dhankani, ${ }^{3}$ Joshua M. Pearce ${ }^{1,2,4^{*}}$ 1. Department of Materials Science \& Engineering, Michigan Technological University

2. Department of Electrical \& Computer Engineering, Michigan Technological University

3. Department of Mechanical Engineering-Engineering Mechanics, Michigan Technological University, Houghton, MI, USA

4. Department of Electronics and Nanoengineering, School of Electrical Engineering, Aalto University, FI-02150 Espoo, Finland

* corresponding author: pearce@mtu.edu

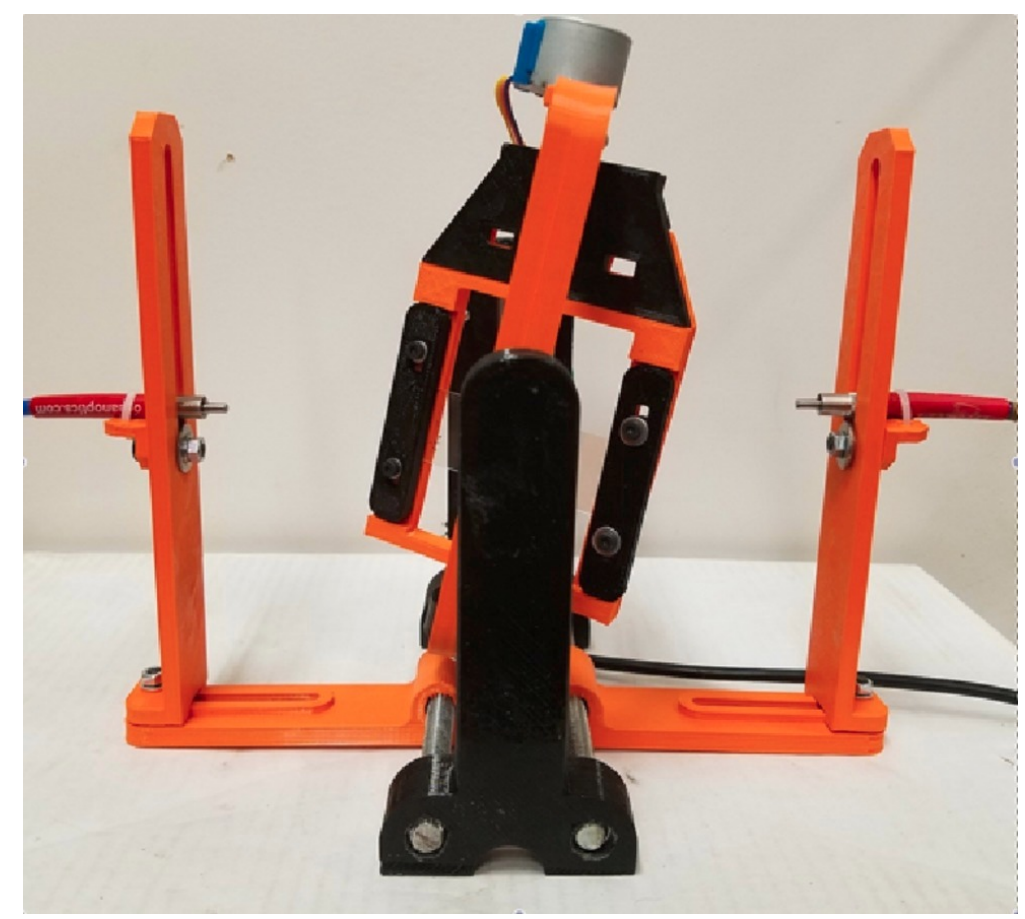

\begin{abstract}
:
Simple 3-D printable open source hardware designs have proven to be effective scientific instruments at low costs. Further development in this area is coupling open source electronics with 3-D printable mechanical components to make fully functional distributedly-manufactured mechatronic tools for science. One research area where such low-cost technology is needed is to characterize thin film anti-reflective coatings and transparent conducting oxides (TCOs) for the glass, mirror and solar photovoltaic industry whose transmission properties are angle dependent. To meet this research need a low-cost 3-D printable open source dual axis gimbal system is presented in this study. An Arduino based microcontroller is used to move the sample holder to the user specified angle where two stepper motors control the motion providing two degrees of freedom. The sample holder is made in such a way that samples can easily be mounted on it by two movable latches. The system was validated and characterized for: i) unidirectional accuracy,
\end{abstract}


Preprint: Nupur Bihari, Smruti Prasad Dash, Karankumar C. Dhankani, Joshua M. Pearce. 3-D printable open source dual axis gimbal system for optoelectronic measurements. Mechatronics 56, 175-187 (2018). DOI:

https://doi.org/10.1016/j.mechatronics.2018.07.005

ii) repeatability, iii) backlash, iv) speed resolution and v) microstep size. Finally, the mechatronic system is tested for the intended application using a halogen light source and a spectrometer to measure transmission through glass TCO samples through a hemisphere. The system performed as expected has a unidirectional accuracy of $2.827^{\circ}$, repeatability of $1.585^{\circ}$, backlash error of $1.237^{\circ}$, maximum speed of $35.156^{\circ}$ and a verifiable microstep size of $0.33^{\circ}$. Despite the highest mean squared errors, the open source gimbal system performed adequately while measuring transmission of radiation through glass with TCO coatings. This open source system also represents a $96 \%$ cost in savings as compared to the least expensive commercial variant. The high mean squared errors are offset by the cost of the system coupled with its open source nature that promotes further collaboration and hence, development.

Keywords: open source hardware; gimbal system; 3-D printing; rotator; optoelectronics; transmittance; FOSH

\section{Introduction}

A high level of modularization [1] in open technology development allows for collaboration in a way that knowledge is efficiently shared by many [2,3]. Free and open source technological development also decreases ambiguity and makes information freely available to a large group of developers [4-6]. This promotes the sharing of knowledge among researchers in dissimilar fields [7], which has led to a number of success stories, notably Linux [8,9] and the rise of free and open source software (FOSS) movement [10-11]. The motivation for development is high when assistance from skilled developers is available [12,13] and the results are favorable [14-18]. Thus, FOSS is now also well established in mechatronics [19-21]. The success of FOSS has encouraged hardware developers to adopt this model as well [22-24]. Free and open source hardware (FOSH) development has seen success with a number of projects including the popularity of accessible microcontrollers such as the Arduino [25], which has been rapidly adopted by researchers in industry and academia [26] for ease of use, high modularization [27], and affordable cost [28-30].

Arduino microcontrollers have been used wearable textile 'e-clothing' with embedded sensors [31-33], complex communication systems for microgrids [34], educational tools [35] such as a mechatronics project based on 3-D printing [36] and home automation control systems [37-39]. Most useful to scientists, Arduino microcontrollers are being used to automate mechatronic equipment in the lab [27,40] including a number of wireless sensor networks [41], air pollution monitoring and control system [42], data sharing and environmental monitoring [43,44], oceanographic sensor and actuator control systems [45-47] and have repeatedly proven that a low cost open source platform has the capability to perform equally well as compared to sophisticated expensive systems $[27,40,48]$. Other mechatronics equipment including quadrotors [49], robot fish [50], and mobile wheeled robots [51] have been developed using Arduino. It is being used as a teaching tool at the undergraduate level in mechatronics laboratories [52] and for developing low-cost educational material [53,54]. 
Preprint: Nupur Bihari, Smruti Prasad Dash, Karankumar C. Dhankani, Joshua M. Pearce. 3-D printable open source dual axis gimbal system for optoelectronic measurements. Mechatronics 56, 175-187 (2018). DOI:

https://doi.org/10.1016/j.mechatronics.2018.07.005

The development of open source 3-D printing in the RepRap project [55] has emerged as one of the primary mechanisms driving FOSH development as the digital designs for 3-D printing can themselves be open sourced [56]. In addition to educational opportunities [57-59], rapid prototyping using 3-D printing has reduced the cost of commonly used scientific equipment while allowing faster development [27,40,60,61]. Much modern experimental scientific research requires expensive equipment that has high maintenance costs. With 3-D printed equipment, this maintenance cost is reduced significantly since most parts can be printed and replaced internally. The plethora of repositories (e.g. NIH 3D Printer Exchange [62], Youmagine [63], MyMiniFactory [64], GrabCAD [65], Thingiverse [66], etc.) available with CAD models of various parts enables low-cost and relatively easy distributed production by consumers [67] and adopted by scientists [40]. One area that is benefiting from 3-D printing is optics with 3-D printed embedded optical elements and interactive devices [68], curved displays [69], phantoms for whole animal optical imaging [70], spectral system for collagen fluorescence lifetime measurements [71], flexure translation stage for open-source microscopy [72], smart phone microscope adapters [73], a 3-D microscope stage [74] and a large customizable library of mechanical components for optics setups [75]. While open source 3-D printing has seen wide acceptance in biology and optics, it remains conspicuously absent from the semiconductor arena. The solar photovoltaic industry in particular relies on reduced costs and quick manufacturing. There is a need to further develop this low-cost open source technology to characterize thin film anti-reflective coatings and transparent conducting oxides (TCO) for the glass, mirror and solar photovoltaic industry [76,77] whose transmission properties are angle dependent [78-79]. The angular and spectral dependence of reflectivity and transmissivity of a material are important parameters that need to be studied for x-ray and other spectroscopic analyses [80]. A gimbal system is often used to rotate the sample in axes to study this angular dependence of optical and optoelectronic properties.

In order to fulfil this research need, a novel low-cost 3-D printable open source dual axis gimbal system is presented in this study. The motivation for this study is to determine if a 3-D printed open hardware system, which reuses component designs from other applications is adequate to perform as an optoelectronic measurement aid while eliminating precision machining used in commercial systems, reducing equipment capital costs, allowing complete control by the user in order to make modifications and meet the needs of custom applications. In the design an Arduino based microcontroller is used to move the sample holder to the user specified angle where two stepper motors control the motion providing two degrees of freedom. The sample holder is made in such a way that sample glass slides can easily be mounted on it by two movable latches. The system was validated and characterized for: i) unidirectional accuracy, ii) repeatability, iii) backlash, iv) speed resolution and v) microstep size. Finally, the mechatronic system is tested for the intended application using a halogen light source and a spectrometer to measure transmission through glass TCO samples through a hemisphere. The results are discussed in the context of the development of open source mechatronic equipment for laboratory use. 
Preprint: Nupur Bihari, Smruti Prasad Dash, Karankumar C. Dhankani, Joshua M. Pearce. 3-D printable open source dual axis gimbal system for optoelectronic measurements. Mechatronics 56, 175-187 (2018). DOI: https://doi.org/10.1016/j.mechatronics.2018.07.005

\section{Materials and methods}

The design methodology used for this device uses an FOSH optimization model previously described [81], which encompasses six design principles: design involving the principles of use of a free and open-source tool chain, minimize the number and type of parts and the complexity of the tools, minimize the amount of material and the cost of production, maximize the use of components that can be 3-D printed, create parametric designs to enable design customization and use of off-the-shelf parts, which are readily available throughout the world. Following these design principles, here, a gimbal system that can automatically test a range of custom angles in an $\mathrm{x}$ and $\mathrm{y}$ axis for use in optical thin film characterization is described. This system was found to have a microstep size of less than 1 degree and repeatability and backlash error of less than 2 degrees.

\subsection{Mechanical Architecture}

The 3-D printed parts were all designed in parametric CAD for ease of customization and to be easily 3-D printed on low-cost desktop 3-D printers. include:

1. The large support structure (Figure 1) has housing for a stepper motor, Adafruit Trinket Pro microcontroller board and the driver boards for the stepper motor. It also includes space for two M8 screws that ensure perfect alignment between the large and small support structures.

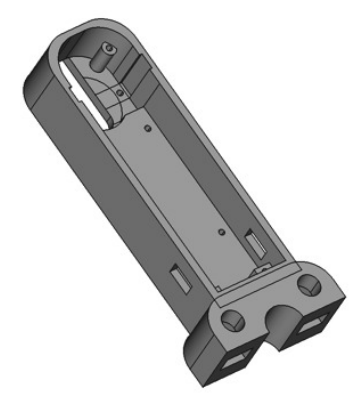

Figure 1: Large 3-D printed support showing casing for stepper motor, microcontroller and driver boards and two M8 screws.

2. The small support structure (Figure 2) does not contain any electronics but ensures that the structure remains flat at all times. It also has the pivot for the $y$-axis of the gimbal. 
Preprint: Nupur Bihari, Smruti Prasad Dash, Karankumar C. Dhankani, Joshua M. Pearce. 3-D printable open source dual axis gimbal system for optoelectronic measurements. Mechatronics 56, 175-187 (2018). DOI: https://doi.org/10.1016/j.mechatronics.2018.07.005

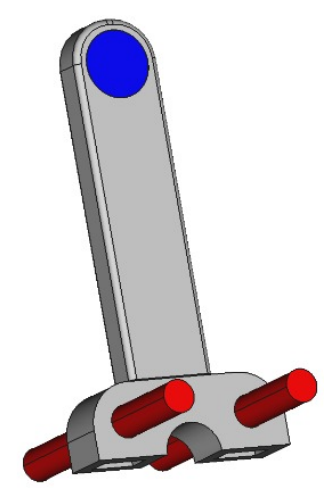

Figure 2. Small 3-D printed support structure showing bearing in blue and two M8 threaded rods in red.

3. The 3-D printed cover (Figure 3) is used to enclose all electronics inside the large support structure. It has two openings for power supply and USB cables. Having a cover ensures correctly connected wires and protects the electronics from the environment.

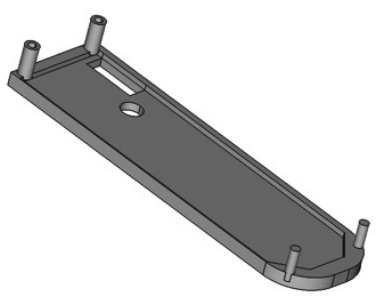

Figure 3. 3-D printed cover showing slots for power supply and USB cables

4. The major platform is the y-axis of the gimbal system shown in Figure 4. This has two pivots that can be attached to the large and small support structures. This also has housing for a stepper motor.

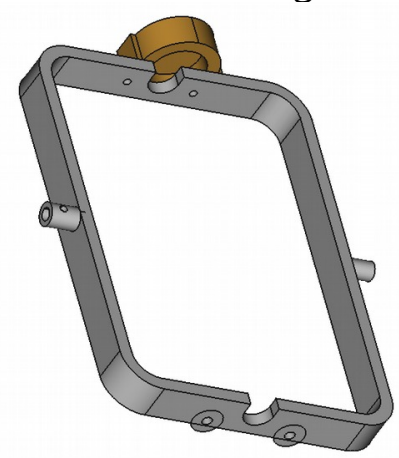

Figure 4. 3-D printed major platform showing pivots and casing for stepper motor

5. The minor platform is the x-axis of the gimbal system and is shown in Figure 5. This has pivots that can be attached to the larger and smaller support structures. This part 
Preprint: Nupur Bihari, Smruti Prasad Dash, Karankumar C. Dhankani, Joshua M. Pearce. 3-D printable open source dual axis gimbal system for optoelectronic measurements. Mechatronics 56, 175-187 (2018). DOI: https://doi.org/10.1016/j.mechatronics.2018.07.005

is also the sample holder and includes slots for fastening the sample latch. Although the design is parametric and can be customized, the current platform holds samples $75 \mathrm{~mm} \times 60 \mathrm{~mm}$ or smaller.

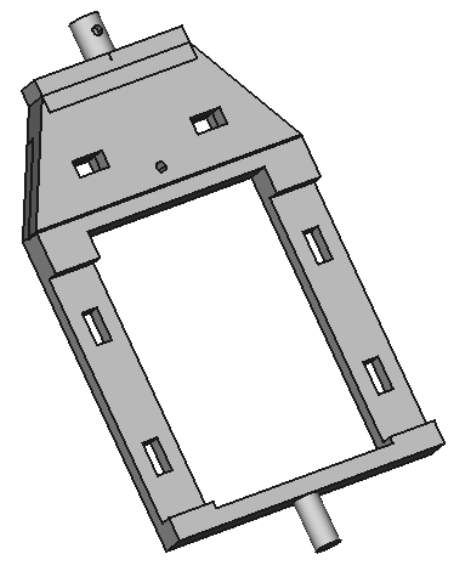

Figure 5. 3-D printed minor platform showing pivots and slots for latches

6. The holder latches (Figure 6) onto the minor platform and provides a stable surface for the sample. This holder as designed in its current dimensions can be used for two plain standard microscope glass slides (25mm x $76 \mathrm{~mm}$ ).

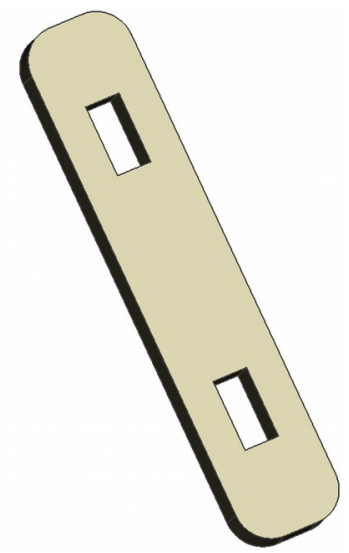

Figure 6. 3-D printed holder showing slots for latches

7. The 3-D printed latches (Figure 7) can be used to fasten the holder to the minor platform. These ensure that the sample stays flat and stationary during the measurement. 
Preprint: Nupur Bihari, Smruti Prasad Dash, Karankumar C. Dhankani, Joshua M. Pearce. 3-D printable open source dual axis gimbal system for optoelectronic measurements. Mechatronics 56, 175-187 (2018). DOI:

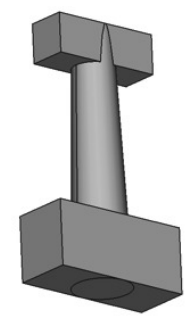

Figure 7. 3-D printed latches to fasten cover to minor platform.

8. Mount base (Figure 8) is used as the foundation on which the alignment apparatus is fixed. This forms the basis of the support structure for fiber optic cables.

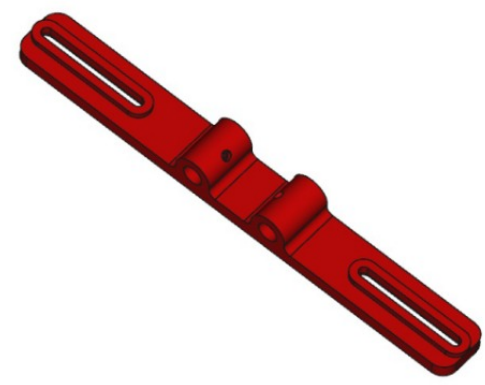

Figure 8. 3-D printed mount base used as the foundation for mount arms.

9. Mount arm (Figure 9) is 3-D printed to the correct height for the fiber optic cable. This is fixed on opposite ends of the mount base. The gap allows the user to change the height of the aligner, and thus the cables.

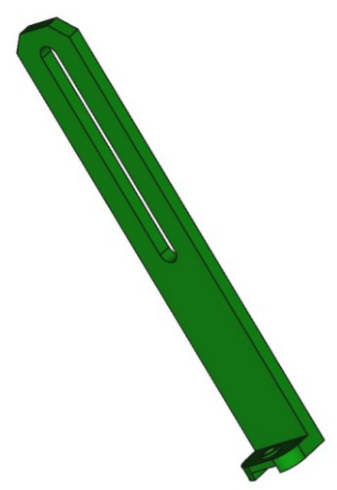

Figure 9. 3-D printed mount arm used to hold the fiber optic cable.

10. Fiber optic aligner (Figure 10) is used to ensure that the fiber optic cables lay flat and the transmitting and the receiving end are always $180^{\circ}$ from each other. 
Preprint: Nupur Bihari, Smruti Prasad Dash, Karankumar C. Dhankani, Joshua M. Pearce. 3-D printable open source dual axis gimbal system for optoelectronic measurements. Mechatronics 56, 175-187 (2018). DOI: https://doi.org/10.1016/j.mechatronics.2018.07.005

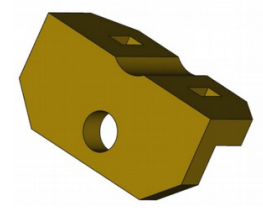

Figure 10. 3-D printed fiber optic aligner is used to fasten the fiber optic cables.

The assembly of these parts is demonstrated in Figure 11.

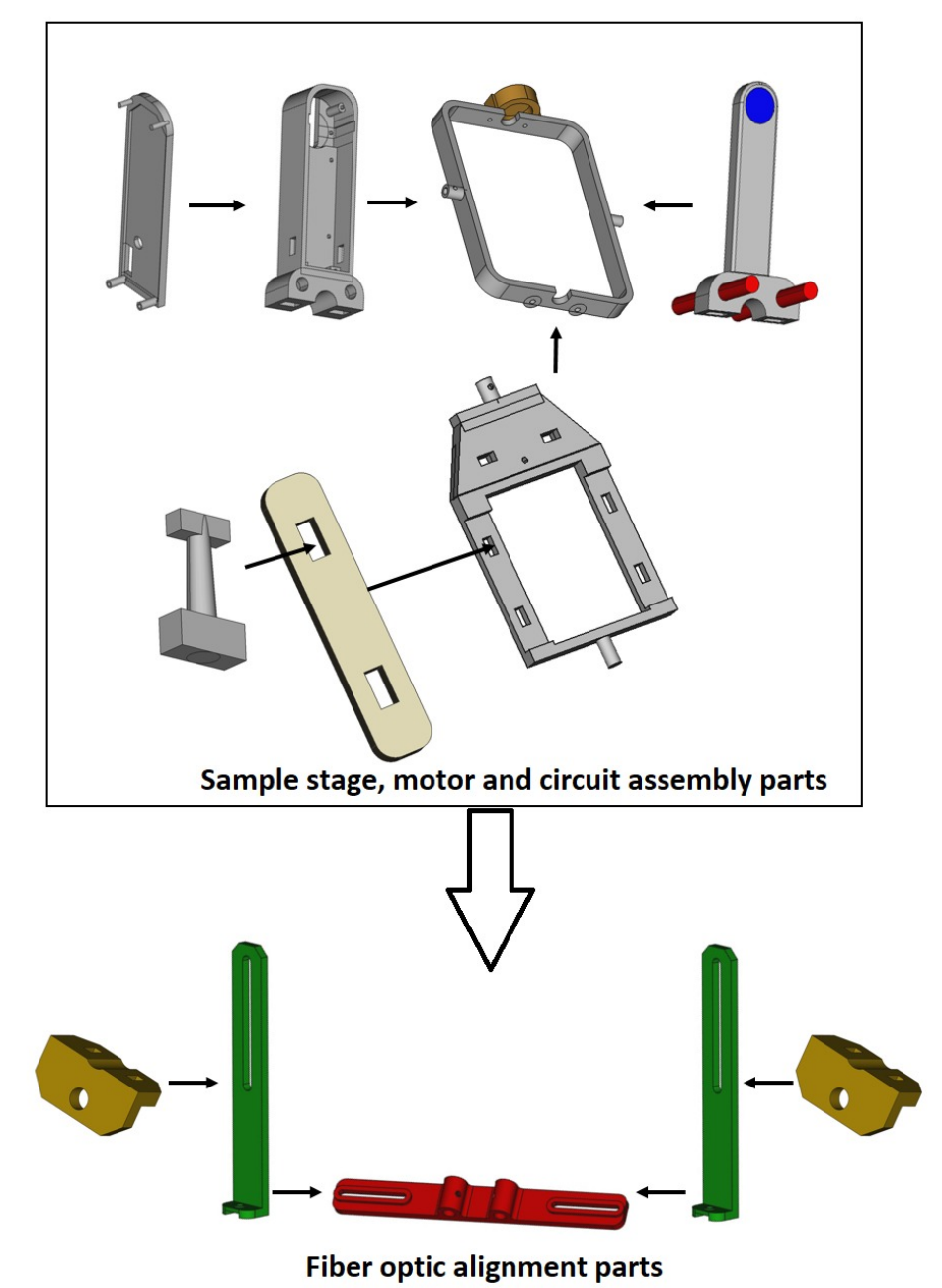

Figure 11. Schematic showing assembly of all 3-D printed parts. The sample stage, motor and circuit assembly parts were constructed before joining them to the supporting fiber optic alignment components.

The complete bill of materials (BOM) is available with design files used to print various parts of the gimbal system [82]. This BOM can be classified into two categories: 3-D printable parts (Table 1) and commercially available hardware (Table 2). All custom parts were designed using 
Preprint: Nupur Bihari, Smruti Prasad Dash, Karankumar C. Dhankani, Joshua M. Pearce. 3-D printable open source dual axis gimbal system for optoelectronic measurements. Mechatronics 56, 175-187 (2018). DOI:

https://doi.org/10.1016/j.mechatronics.2018.07.005

version 0.15 of FreeCAD [83], an open source parametric 3-D CAD modeler. These parts were designed parametrically and can be customized easily by the user. Polylactic acid (PLA) filament purchased commercially [84] was used with an open source delta style RepRap 3-D printer [85], which was controlled by the open source Franklin 3-D printer controller [86]. However, any hard thermoplastic can be used on any fused filament fabrication (FFF)-based desktop 3-D printer. The expected operating environment was indoor laboratory space with an ambient temperature between $20^{\circ} \mathrm{C}$ and $25^{\circ} \mathrm{C}$. Thermal expansion of 3-D printing polymer was thus not taken into consideration while determining part dimensions. A tolerance of $0.1 \mathrm{~mm}$ was used to ensure parts fit snugly without the possibility of cracking or loosening.

The price of a $1 \mathrm{~kg}$ PLA filament spool on November 17, 2017 was used for the cost analysis. Off-the-shelf parts were procured from Amazon.com or similar.

Table 1. Customized 3-D printable parts for the open source dual axis Gimbal system.

\begin{tabular}{llccc}
\multicolumn{1}{c}{ Part } & $\begin{array}{c}\text { Quantit } \\
\text { y }\end{array}$ & $\begin{array}{c}\text { PLA Mass (g) } \\
\text { (15\% infill) }\end{array}$ & $\begin{array}{c}\text { Cost } \\
\text { (USD) }\end{array}$ \\
1 & Large Support & 1 & 22 & 0.64 \\
2 & Small Support & 1 & 38 & 1.10 \\
3 & Cover & 1 & 18 & 0.52 \\
4 & Major Platform & 1 & 38 & 1.10 \\
5 & Minor Platform & 1 & 38 & 1.10 \\
6 & Holder & 1 & 6 & 0.17 \\
7 & Latch & 2 & 2 & 0.12 \\
8 & Mount Base & 1 & 32 & 0.93 \\
9 & Mount Arm & 2 & 20 & 1.16 \\
1 & Fiber Optic Aligner & 2 & 2 & 0.12 \\
0 & & & &
\end{tabular}

Total

6.96 
Preprint: Nupur Bihari, Smruti Prasad Dash, Karankumar C. Dhankani, Joshua M. Pearce. 3-D printable open source dual axis gimbal system for optoelectronic measurements. Mechatronics 56, 175-187 (2018). DOI:

https://doi.org/10.1016/j.mechatronics.2018.07.005

Table 2. Commercially available parts for the open source dual axis Gimbal system

Component

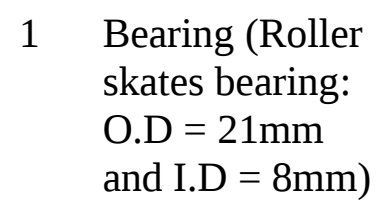
2 5V Stepper
Motor and
Driver

$3 \begin{array}{ll}\text { Adafruit Pro } \\ \text { Trinket 5V } \\ \text { Microcontroller } \\ 4 \text { 5/16” (or M8) } \\ \text { screw 195mm } \\ 5 & 5 / 16 ” \text { (or M8) }\end{array}$

5 5/16” (or M8)

nuts

6 5V DC Supply

Adaptor

$7 \quad 5.5 \mathrm{~mm}$ Jack

Connector

Socket

8 M5 Socket Head

Bolt 16mm

$9 \quad$ M5 Steel Hex

Nut

10 M3 Heat Set

Insert

11 M3 Socket Head

Screw

12 8" Cable Tie

\section{Total}

2

2

1

2

6

1

1

4

4

2

2

2

(017.

2.90

Hardware Store

5.60

Amazon.com*

9.95

Amazon.com*

2.80

Hardware Store

$0.60 \quad$ Hardware Store

10.99 Amazon.com*

1.03 Amazon.com*

0.48

Hardware Store

0.07 Hardware Store

$0.25 \quad$ Hardware Store

$0.14 \quad$ Hardware Store

0.06

34.87

*Prices when ordered in April 2017.

As can be seen from the sum total of the BOM from Tables 1 and 2 the total hardware cost is USD \$41.83. It should be noted that the cost of PLA filament has been reduced recently and this should be viewed as an upper cost limit.

The assembled gimbal system was then set up between a fiber optic light source and detector as shown in Figure 12. 
Preprint: Nupur Bihari, Smruti Prasad Dash, Karankumar C. Dhankani, Joshua M. Pearce. 3-D printable open source dual axis gimbal system for optoelectronic measurements. Mechatronics 56, 175-187 (2018). DOI:

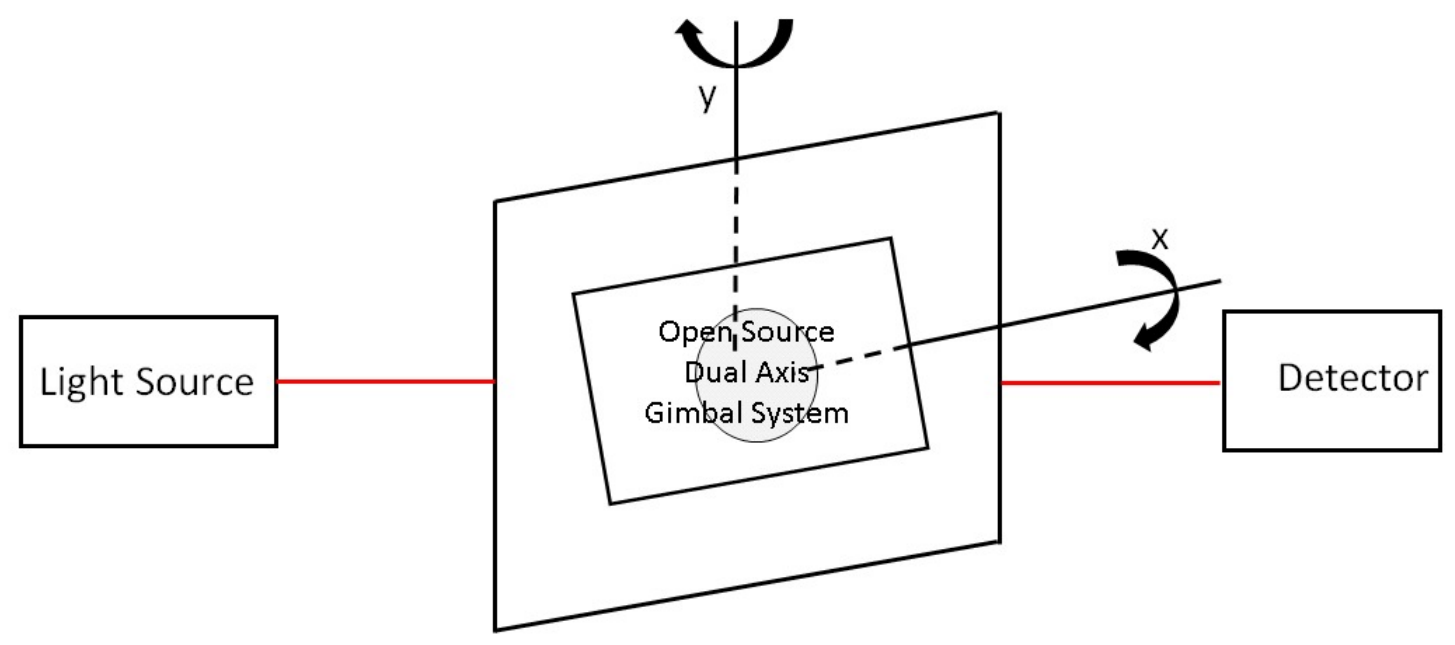

Figure 12. Schematic showing placement of the open source dual axis gimbal system equidistant from a fiber optic light source and detector. The axes of rotation are also shown. The optical path is highlighted in red.

\subsection{Electronic Architecture}

An Adafruit Trinket Pro 5V 16MHz with ATmega328 common core Arduino chip was obtained from Adafruit Industries. This development board features micro-USB jack that was used for uploading the program to the system memory. Two Elegoo 28BY J-48 ULN2003 5V stepper motors were used to move the major and minor platforms in y and $\mathrm{x}$ axes respectively. Two ULN2003 driver boards for Arduino were used to control these stepper motors. The circuit schematic is shown in Figure 13. 
Preprint: Nupur Bihari, Smruti Prasad Dash, Karankumar C. Dhankani, Joshua M. Pearce. 3-D printable open source dual axis gimbal system for optoelectronic measurements. Mechatronics 56, 175-187 (2018). DOI: https://doi.org/10.1016/j.mechatronics.2018.07.005

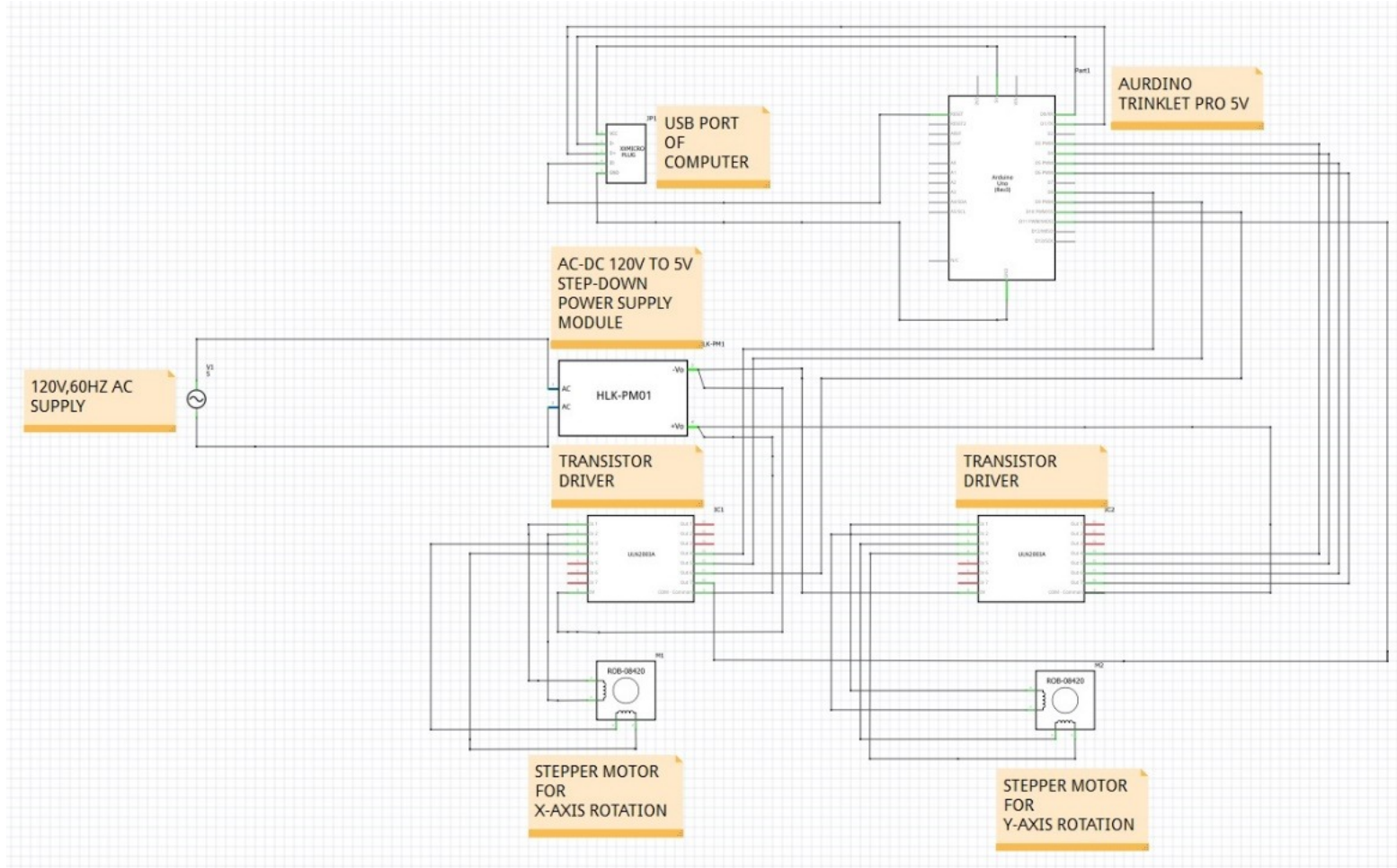

Figure 13: Circuit schematic of open source gimbal system showing interconnects between Arduino microcontroller, power supply and drivers.

\subsection{Software Architecture}

The system runs on a sketch file written for Adafruit Trinket Pro 5V and available on the Open Science Framework [82]. The user is prompted to choose a terminal x-y coordinate or a trace between the initial and the user provided final $x-y$ coordinates. The tracing feature moves in steps of ten degrees. However, this can be easily changed in the code. Figure 14 shows a flowchart describing programming logic and the pseudocode written below describes the stepper motor control.

//Pseudo code for Gimbal system

1. Initiate device

2. Obtain mode of operation (user input: "1" for commanded angle and "2" for trace)

3. if mode $==1$

1. Obtain desired $X$ axis angle (user input)

2. Move stepper in $\mathrm{X}$ axis to desired angle

3. Update $\mathrm{X}$ axis location

4. Obtain desired $\mathrm{Y}$ axis angle (user input)

5. Move stepper in Y axis to desired angle

6. Update y axis location 
Preprint: Nupur Bihari, Smruti Prasad Dash, Karankumar C. Dhankani, Joshua M. Pearce. 3-D printable open source dual axis gimbal system for optoelectronic measurements. Mechatronics 56, 175-187 (2018). DOI: https://doi.org/10.1016/j.mechatronics.2018.07.005

4. $\quad$ else if mode $==2$

1. Obtain desired target $X$ axis angle (user input)

2. Obtain desired target $\mathrm{Y}$ axis angle (user input)

3. Loop Y angle from zero to $\mathrm{Y}$ target in specified steps

1. Loop $X$ angle from zero to $X$ target in specified steps

1. Move stepper in $\mathrm{Y}$ axis to next angle

2. Update $\mathrm{Y}$ axis location

3. Move stepper in $X$ axis to next angle

4. Update $X$ axis location

5. else display error (must enter either "1" or "2") 
Preprint: Nupur Bihari, Smruti Prasad Dash, Karankumar C. Dhankani, Joshua M. Pearce. 3-D printable open source dual axis gimbal system for optoelectronic measurements. Mechatronics 56, 175-187 (2018). DOI: https://doi.org/10.1016/j.mechatronics.2018.07.005

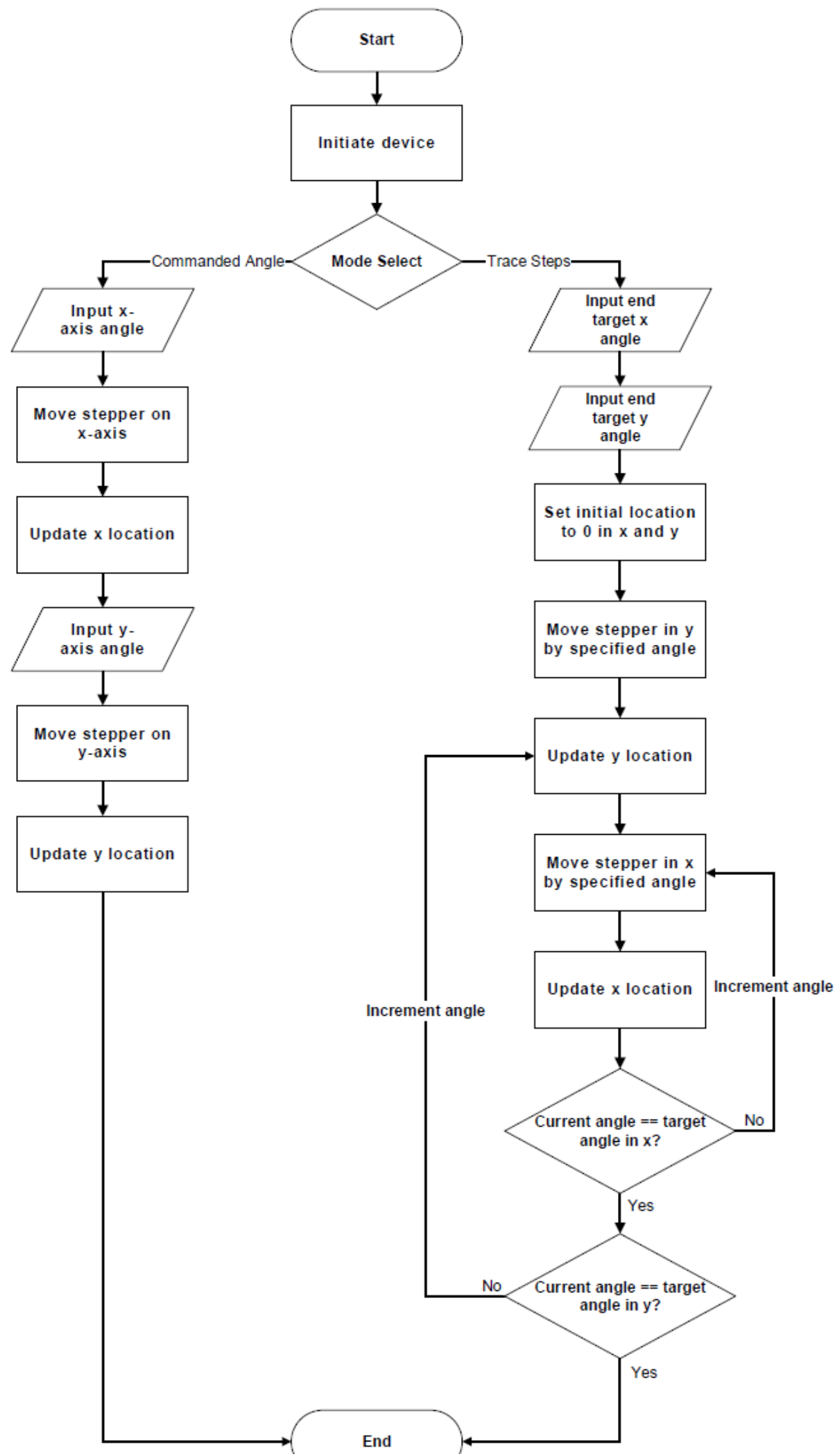


Preprint: Nupur Bihari, Smruti Prasad Dash, Karankumar C. Dhankani, Joshua M. Pearce. 3-D printable open source dual axis gimbal system for optoelectronic measurements. Mechatronics 56, 175-187 (2018). DOI:

https://doi.org/10.1016/j.mechatronics.2018.07.005

Figure 14. Flowchart showing logic used by the microcontroller to move the major and minor platforms on $\mathrm{y}$ and $\mathrm{x}$ axes respectively

The intended purpose of this system is to measure angle dependent transmission properties of thin films on glass substrates. This angle dependence can be accurately recorded using any computer running Arduino Integrated Development Environment’s (IDE) Serial Monitor [87]. Alternatively, this data can be written to files for platform independent access.

\section{Validation and Demonstration}

The gimbal system was tested using an Ocean Optics DH-2000 UV-VIS-NIR halogen light source. An Ocean Optics QP600-2-VIS-NIR fiber optic patch cable was used with a USB2000+ spectrometer. Spectra Suite was used to collect transmission data over the visible spectrum, from wavelength $400 \mathrm{~nm}$ to $800 \mathrm{~nm}$. Data was collected at angles $[\mathrm{x}, \mathrm{y}]:[0,0]$ to $[60,60]$ in steps of 10 degrees.

25mm x 76mm plain glass microscope slides were obtained from VWR International in a thickness of $1 \mathrm{~mm}$. These were cleaned using acetone, 2-propanol and DI water, nitrogen dried, and were mounted on the sample holder of the gimbal system.

The gimbal system was positioned between the light source and the detector such that the source and detector were both equidistant from the sample. This length was kept constant for all measurements. Care was taken to ensure that there were minimal bends in the optical fiber cable, both on the source and the detector side.

There were five major parameters identified for system characterization: 1) unidirectional accuracy, 2) repeatability, 3) backlash, 4) speed resolution and 5) microstep size [88, 89]. These parameters provide characterization metrics needed by users when sourcing a research system. These metrics are used by manufacturers and are part of the standard specification sheets of commercial products with similar functionality and applications.

The unidirectional accuracy was the error in moving between two positions, when approached from the same direction. This was experimentally determined by moving the stepper motor to a commanded angle from two different initial positions and measuring the angle in each case. For repeatability, the same measurement was made six times each in $\mathrm{x}$ and $\mathrm{y}$ directions and the errors in final positions were calculated [90].

These measurements were made by placing the gimbal system at a chosen distance of $85 \mathrm{~cm}$ from a wall and using the projection from a laser as shown in Figure 15. The system was rotated to a specified angle after installing a visible laser on it. The distance from the floor to the point on the 
Preprint: Nupur Bihari, Smruti Prasad Dash, Karankumar C. Dhankani, Joshua M. Pearce. 3-D printable open source dual axis gimbal system for optoelectronic measurements. Mechatronics 56, 175-187 (2018). DOI:

https://doi.org/10.1016/j.mechatronics.2018.07.005

wall at which the beam was visible was measured using a tape-measure. The inverse tangent of the distances measured was used to calculate the physical angle (Figure 15).

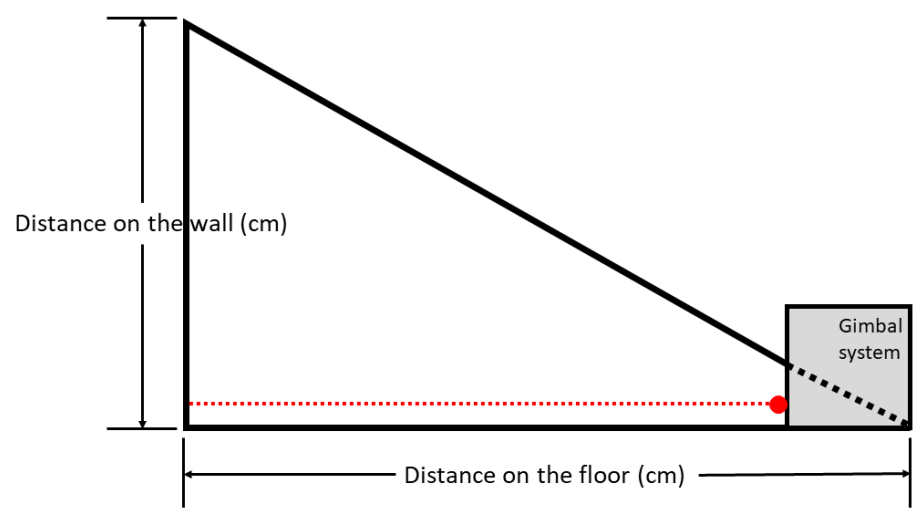

Figure 15. Schematic of the system used for calculating physical angle. The laser mounted on the gimbal system is represented by the red dot with the red dotted line representing the path of the laser beam. The laser beam was at an angle of $0^{\circ}$ from the base for this test.

Backlash was defined as the maximum error when the same final position is approached from two different directions. This was experimentally determined by commanding the stepper motor to move from two different initial angles to a final angle such that:

initial angle $1>$ final angle $>$ initial angle $\quad 2 \quad$ initial angle $1>$ final angle >initial angle 2 [91].

Speed resolution was defined as the smallest incremental change in speed that can be achieved by the system [92]. This was recognized due to its importance in reducing time required to run a set of tests. After moving from an 'initial angle' to a 'final angle', the user's need to move to a different angle (final angle $+\Delta$ angle) from that 'final angle' was seen. The speed at which this incremental change happened was crucial for a given test.

Step and micro-stepping are used to describe stepper motor movement in accordance with the terminology used by component manufacturers. Microstep size is defined as the measured angle divided by the number of states per step allowed by the motor in commanded angle mode. The motors were operated in 8-step sequence with 64 steps per turn [93]. Number of states refers to whether the motor is being operated in full-step mode or half-step mode. In the half-step mode, the motor has 8 states - referring to 8 possible configurations of the transistors. Discussion using states is only made to delineate the stepping pattern. While the "microstep" size is 64 is the number of steps required for a full turn of the motor, the number of steps required for a complete 360 degree rotation of the axes is specified as step size, which is 2048. 
Preprint: Nupur Bihari, Smruti Prasad Dash, Karankumar C. Dhankani, Joshua M. Pearce. 3-D printable open source dual axis gimbal system for optoelectronic measurements. Mechatronics 56, 175-187 (2018). DOI: https://doi.org/10.1016/j.mechatronics.2018.07.005

\section{Results}

A photograph of the complete open source gimbal system with a TCO sample as used for transmission measurements is shown in Figure 16. As can be seen in Figure 16, the system is completely novel compared to commercial counterparts. The open source gimbal system 3-D printed system has no precision-machined metal parts and uses no metal other than fasteners. This enables radical reduction in costs and enables distributed manufacturing and ease of customizability at the expense of characteristics such as unidirectional accuracy and repeatability as quantified below.

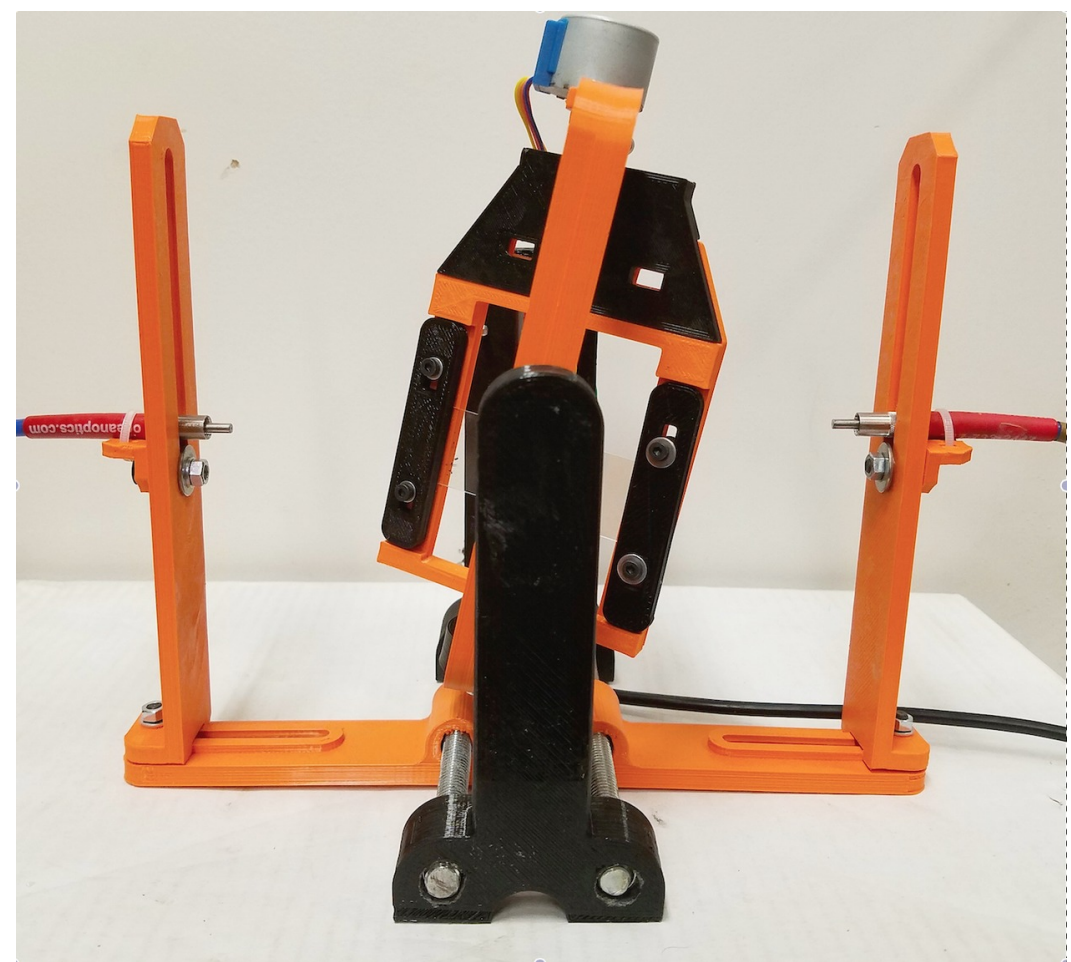

Figure 16. Open source gimbal system used for transmission measurement. A set of aligned fiber optic cables is seen with a sample mounted on the rotating gimbal stage. The fiber optic cables are secured with cable ties as shown.

\subsection{Demonstration of Angular Dependence of Transmission}

The angular dependence of transmission could be quantified using the gimbal system by integrating intensity recorded by the detector from $400 \mathrm{~nm}$ to $800 \mathrm{~nm}$. The clear glass sample had a transmission as shown in Figure 17. This control sample shows a decline in transmission between $30^{\circ}$ and $60^{\circ}$ (in $\mathrm{x}$ ) due to partial screening of the light beam by the physical placement of stepper motors. This effect is accounted for in all samples. A smaller percentage of light is transmitted in the $30^{\circ}$ to $60^{\circ}$ range due to this shading effect. To obtain those equivalent angles the sample can be rotated in the $\mathrm{z}$ axis $180^{\circ}$ and the same scan run. If the transmittance of a 
Preprint: Nupur Bihari, Smruti Prasad Dash, Karankumar C. Dhankani, Joshua M. Pearce. 3-D printable open source dual axis gimbal system for optoelectronic measurements. Mechatronics 56, 175-187 (2018). DOI:

https://doi.org/10.1016/j.mechatronics.2018.07.005

specific point on the sample is desired, appropriate positioning can help, although the error in measurement may be high. Multiple measurements may be made in this angular region to gather statistically significant data. The same final position may also be approached from two different directions in order to get this statistical data while accounting for the backlash error. This shading effect is important to consider when detected intensities are important. However, if only the detection of presence or absence of a bright source of radiation is desired, the gimbal system can be used over its entire angular range.

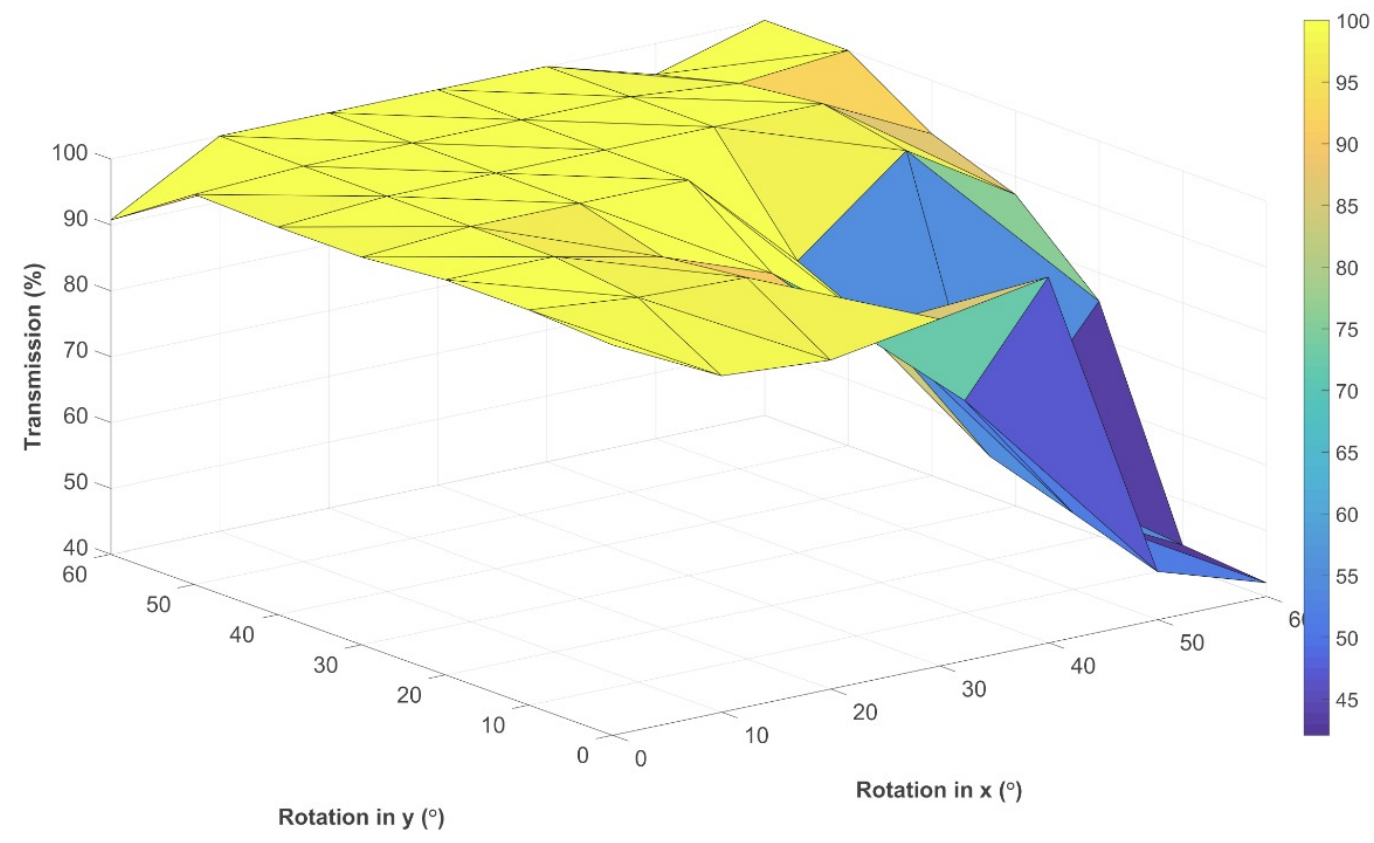

Figure 17. Angular dependence of transmission through a glass sample between $(\mathrm{x}, \mathrm{y})=0$ to $60^{\circ}$. Note that the transmission is only shown from $40 \%$ to $100 \%$. The lowest recorded value of transmission in the $0-60^{\circ}$ range was $42 \%$.

\section{2: Unidirectional Accuracy:}

The largest recorded error was during the movement of $\mathrm{x}$ with a constant value of $\mathrm{y}$ in forward and reverse directions. The root mean squared (RMS) absolute error in position was determined to be 2.827. In contrast, the movement of y axis with a constant $\mathrm{x}$ yielded much lower RMS errors of 1.849 and 1.637 in the forward and reverse directions respectively. The results from the highest error configuration are shown in Figure 18. It should be noted the x-axis is more limited in its range as compared to the $y$-axis in the described configuration of the system. The $\mathrm{x}$-stage is also smaller and lighter than the y-stage, making it more prone to shift slightly when y-stage is moved. To compensate for this, tighter fittings were used to ensure x-stage stays in place as compared to the y-stage. As the large range of the y-stage was of interest for running experiments, this was exploited more in the system leading to a slight loosening of y-stage 
Preprint: Nupur Bihari, Smruti Prasad Dash, Karankumar C. Dhankani, Joshua M. Pearce. 3-D printable open source dual axis gimbal system for optoelectronic measurements. Mechatronics 56, 175-187 (2018). DOI: https://doi.org/10.1016/j.mechatronics.2018.07.005

fittings. While error in the intermediate angle range is kept almost the same for both $\mathrm{x}$ and $\mathrm{y}$ axes, towards the extreme angles this becomes more apparent.

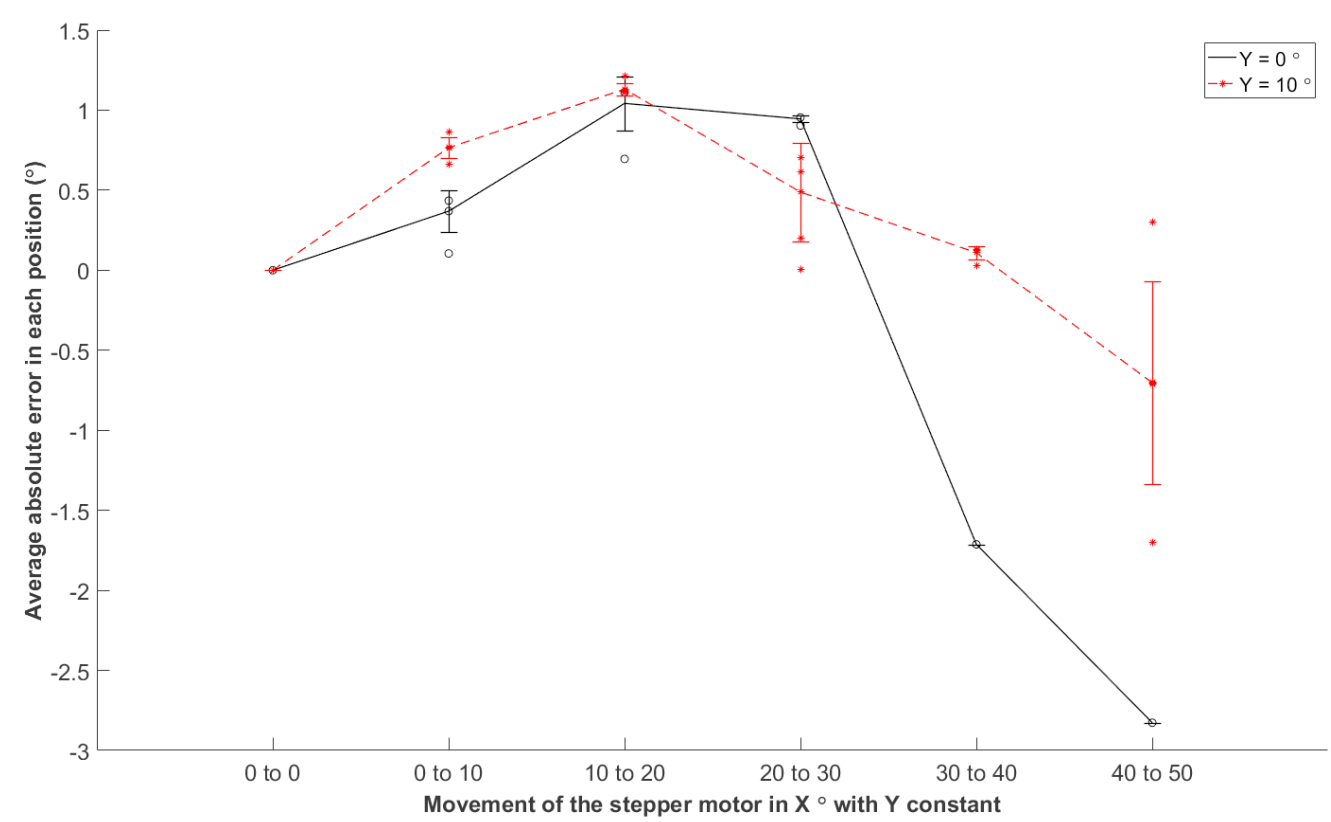

Figure 18. Unidirectional accuracy of the gimbal system with movement in $x$ direction while holding y constant was found to be the least of all test cases. The root mean squared error value of all points was calculated. It was found to be the highest when $\mathrm{x}$ was moved from $40^{\circ}$ to $50^{\circ}$ with y constant at $0^{\circ}$. Interestingly the same high value of error was recorded when the $\mathrm{x}$ axis motor was moved in the reverse direction from $50^{\circ}$ to $40^{\circ}$ with y constant at $0^{\circ}$.

\section{3: Repeatability:}

Six iterations of the experiment defined above were made in both forward and reverse directions (Figure 19). The root mean squared values of error in position of each movement category about the horizontal at zero were calculated as a way to quantify the disparity in position recorded during all 6 iterations. The highest repeatability was recorded for the movement of $y$ in the forward direction when $\mathrm{x}$ is held constant. In contrast, the movement of $\mathrm{x}$ in the reverse direction when $y$ is held constant was found to be the least repeatable. 
Preprint: Nupur Bihari, Smruti Prasad Dash, Karankumar C. Dhankani, Joshua M. Pearce. 3-D printable open source dual axis gimbal system for optoelectronic measurements. Mechatronics 56, 175-187 (2018). DOI: https://doi.org/10.1016/j.mechatronics.2018.07.005

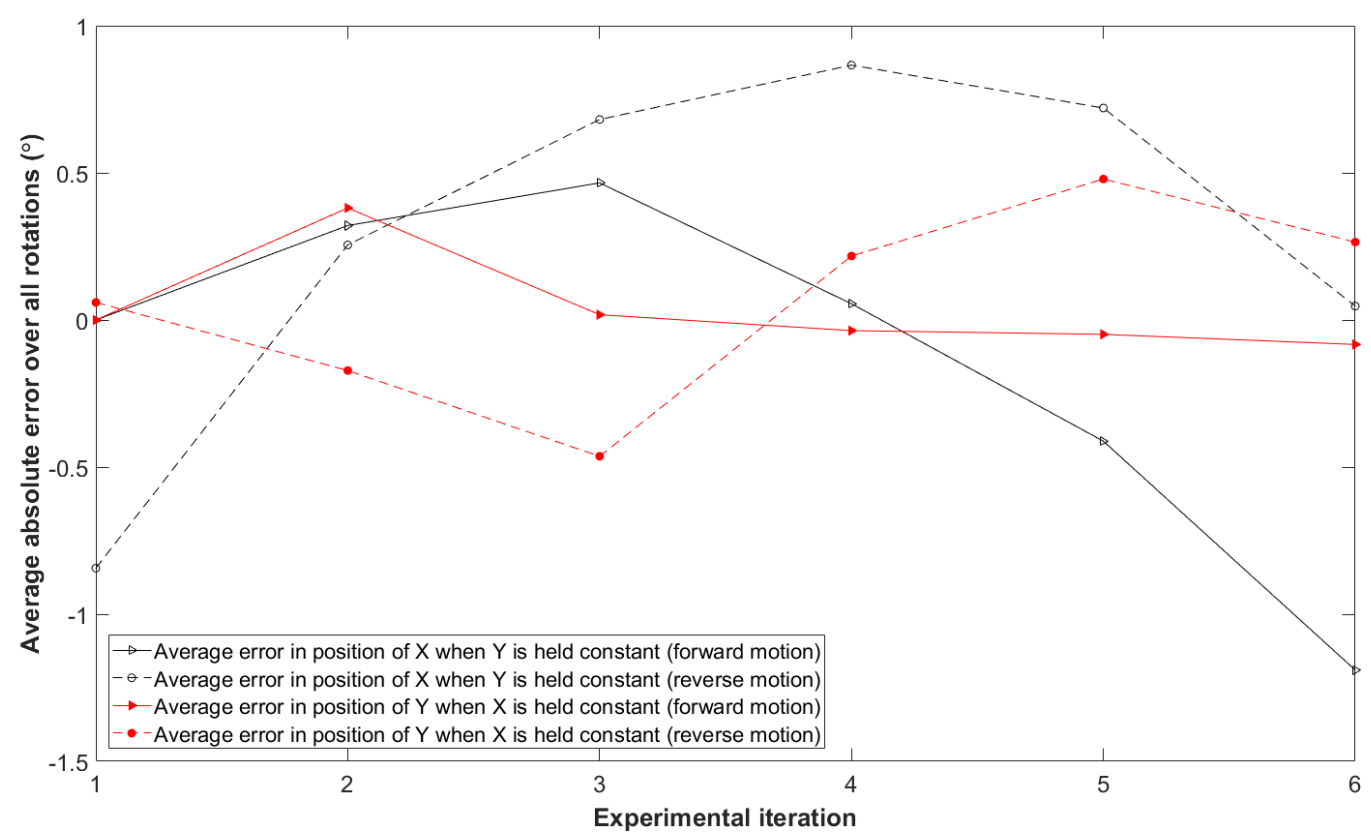

Figure 19. Repeatability was highest during the movement of $\mathrm{y}$ in the forward direction with $\mathrm{x}$ held constant. The RMS error recorded in this case was the least at 0.3950 . The least repeatable condition was the movement of $\mathrm{x}$ when $\mathrm{y}$ is held constant $(\mathrm{RMS}=1.5850)$.

\section{4: Backlash:}

Backlash was quantified using the average errors across all 6 iterations when approaching the same final position from the forward and the reverse directions. During the movement of $\mathrm{x}$ (with y constant) to a final position of $50^{\circ}$ the RMS error recorded was the highest at 1.237. This is visualized as the length of the error bars in Figure 20. The least error was recorded for movement of $\mathrm{y}$ axis to $0^{\circ}$ with $\mathrm{x}$ held constant $(\mathrm{RMS}=0.059)$. 
Preprint: Nupur Bihari, Smruti Prasad Dash, Karankumar C. Dhankani, Joshua M. Pearce. 3-D printable open source dual axis gimbal system for optoelectronic measurements. Mechatronics 56, 175-187 (2018). DOI: https://doi.org/10.1016/j.mechatronics.2018.07.005

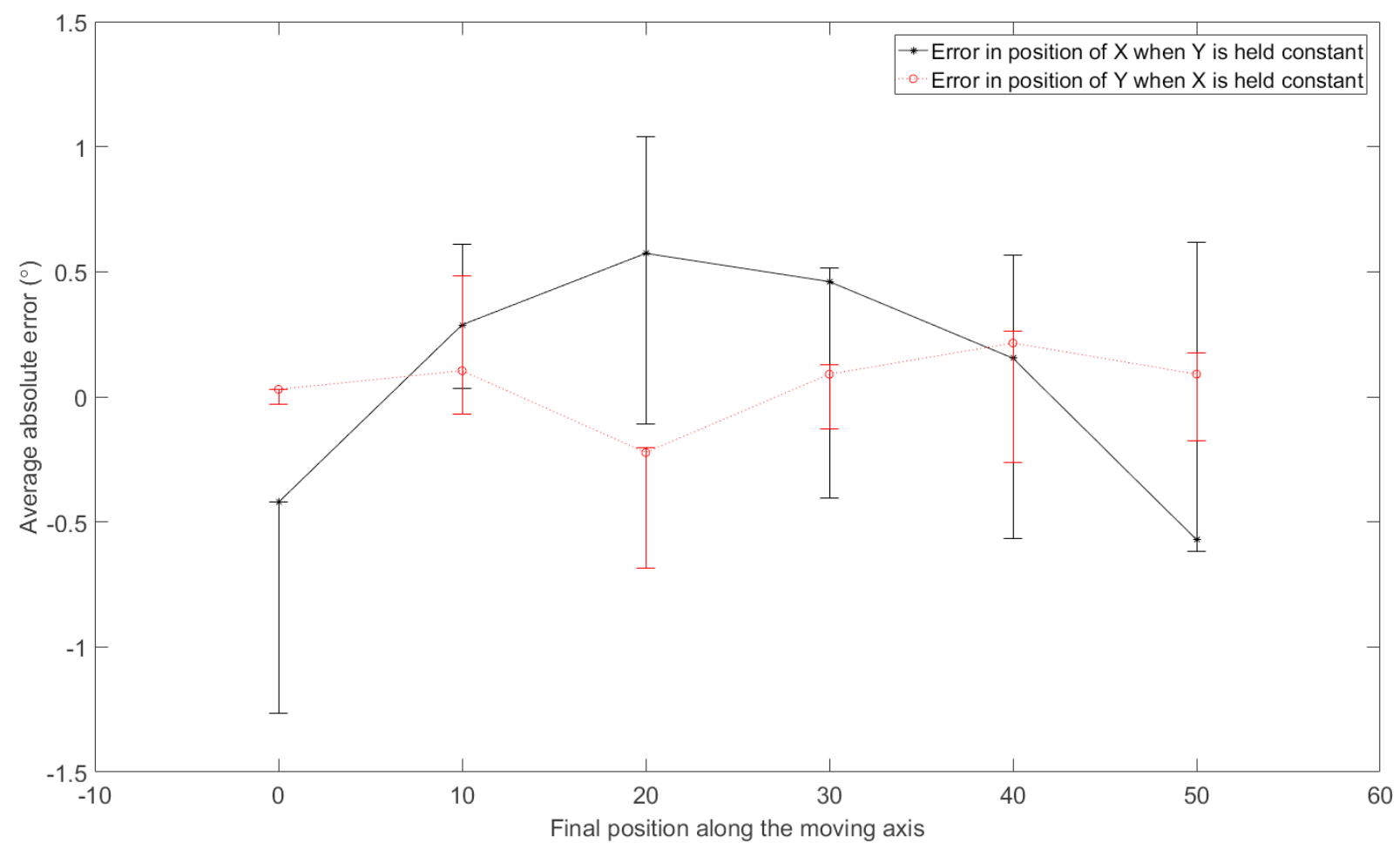

Figure 20. Backlash analysis yielded lowest error when a final position of $0^{\circ}$ was approached by $\mathrm{y}$ with $\mathrm{x}$ held constant. In contrast, the highest error was recorded when $\mathrm{x}$ was moved to a final position of $50^{\circ}$. The top and bottom of the error bar represents the error in forward and reverse movement respectively. Hence the size of the error bar represents total backlash.

\section{5: Maximum Speed:}

The 5V stepper motor used 2048 steps to complete a $360^{\circ}$ rotation. Hence, each step was calculated to be $0.175^{\circ}$. The maximum speed set up in the software was 200 steps per second. Multiple attempts were made increase this speed, however, a grinding noise was observed when the speed was increased beyond 200 steps per second. This was equivalent to a maximum motor speed of $35.156^{\circ}$ per second.

\section{6: Speed resolution:}

The smallest incremental change in speed that could be measured was limited by the experimental constraints chosen for the transmission measurement of interest to the authors. The smallest recorded change was between $0.33^{\circ}$ and $1.01^{\circ}$ per second, which translated to a horizontal distance of $85 \mathrm{~cm}$ and a vertical displacement of $1.5 \mathrm{~cm} \pm 0.5$ as shown in Figure 15 . Hence, the smallest measureable increment in steps was between 2 and 5 steps.

\section{7: Micro step Size:}


Preprint: Nupur Bihari, Smruti Prasad Dash, Karankumar C. Dhankani, Joshua M. Pearce. 3-D printable open source dual axis gimbal system for optoelectronic measurements. Mechatronics 56, 175-187 (2018). DOI: https://doi.org/10.1016/j.mechatronics.2018.07.005

Microstep size was determined by dividing the angle by the number of allowed states. Alternatively it was calculated by multiplying the steps per revolution of the motor by the number of allowed states. In this case the multiplier was 8 . Since each revolution of the axes corresponded to 2048 steps, the microstepping was determined to be 16,384 steps per revolution, or $0.022^{\circ}$ per step. While this is_theoretically true, as stated in section 4.6 , experimentally, a change in angle smaller than $0.33^{\circ}$ could not be verified.

\section{$\underline{4.8 \text { Angular Limitations }}$}

The angular rotation domain of the gimbal system can be visualized as seen in Figure 21 . The shaded area represents the unhindered motion of the $\mathrm{x}$ and $\mathrm{y}$ axes together. Due to the design of this system other angles, while being partly accessible, may not allow adequate brightness in the transmission setup for optical measurements. The placement of the stepper motors and the frame obstructs the line of sight from the light source to the detector through the sample holder. However experimental results stated above show that the system could be used for optical measurements when targeted angles lie in the shaded regions.

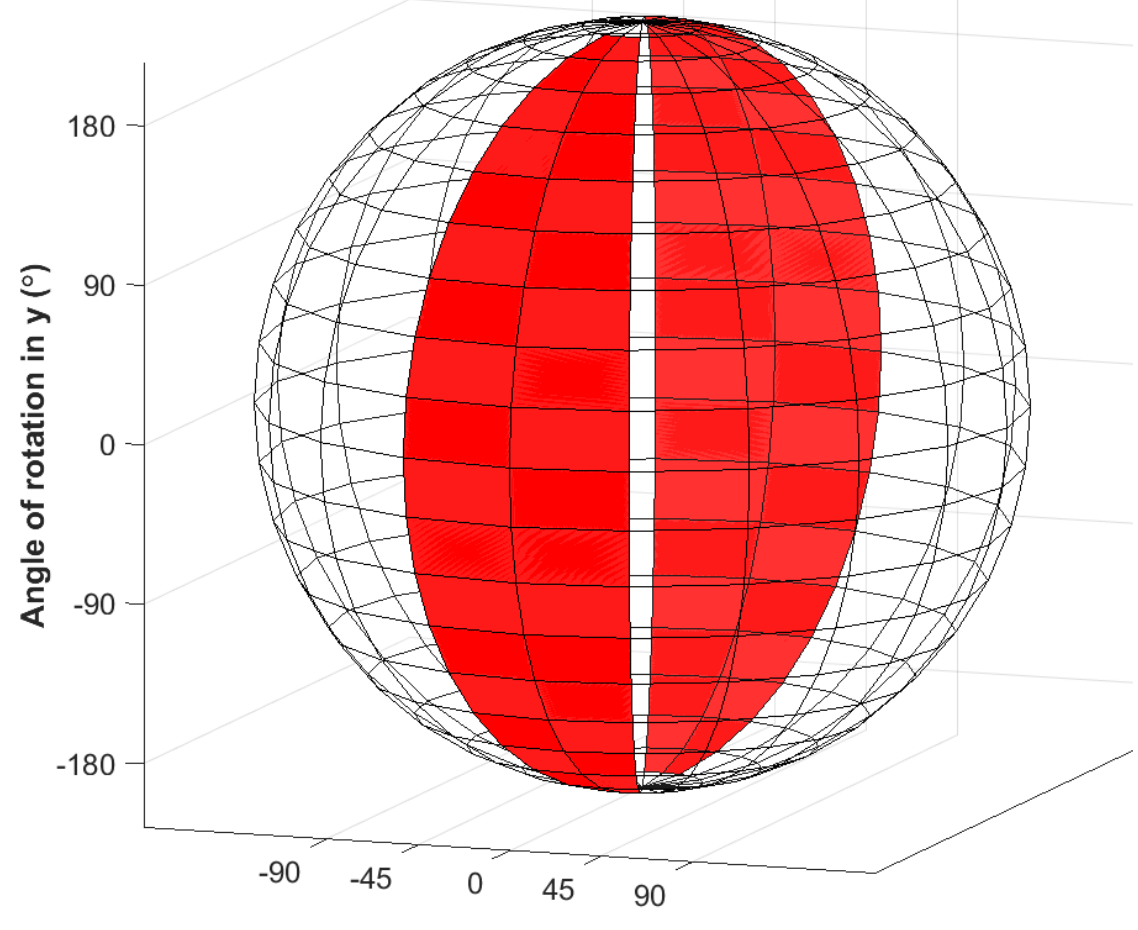

Angle of rotation in $\times\left({ }^{\circ}\right)$

Figure 21. The shaded area represents the allowed motion of motors in both $\mathrm{x}$ and $\mathrm{y}$ directions while keeping adequate intensity at the detector for optical measurements. While angular limitation in the $\mathrm{y}$ direction is $-180^{\circ}$ to $180^{\circ}$, it is $-45^{\circ}$ to $45^{\circ}$ in the $\mathrm{x}$ direction. 
Preprint: Nupur Bihari, Smruti Prasad Dash, Karankumar C. Dhankani, Joshua M. Pearce. 3-D printable open source dual axis gimbal system for optoelectronic measurements. Mechatronics 56, 175-187 (2018). DOI:

https://doi.org/10.1016/j.mechatronics.2018.07.005

\section{Discussion}

The total cost of materials of the open source gimbal system is $\$ 41.83$, which is compared to the commercial systems already in the market shown in Table 3. As can be seen by Table 3, the open source gimbal system represents $95 \%$ or more savings from commercial systems. These cost savings are based on comparison of the material costs of the open source system to the retail price of the commercial systems. Thus, for the open source system there is no labor cost calculated for the purchasing of components, 3-D printing, and assembly. Each of these assumptions can be analyzed carefully. First, ignoring labor costs are relevant in the following situations: (1) where the 3-D printing and the assembly of the device is used as a learning aide for the construction of scientific equipment, open hardware or as part of a course [59, 94]; (2) where the labor is provided by unpaid interns or volunteers such as undergraduates trying to gain research experience and improve their resume or curriculum vitae; or, (3) where there is no opportunity cost to using existing salaried employee (e.g., the use of a lab manager or assistant or other position that is paid a fixed cost for all tasks conducted in a particular lab space, and for which there is no opportunity cost for them working on the fabrication of the device). At academic institutions such as colleges and universities these conditions can be readily met in most labs. In other labs, where this is not the case it is instructive to at the look at the potential cost of labor for the fabrication of the open source gimbal system. The labor involved is represented by three tasks: (1) 3-D printing the ten 3-D printed parts listed in Table 1, (2) purchasing the 12 components listed in Table 2; and (3) assembling the device and installing the software when all of the components have been gathered. The labor for each of these tasks will be analyzed separately, below using the lowest cost skill level employee.

First, the components listed in Table 1 must be 3-D printed and due to the mass proliferation of FFF RepRap based 3-D printers [95], this can now be considered a relatively low-skilled task [96]. The designs have already been made are easily downloaded, pre-oriented and ready to be sent to a pre-calibrated FFF based 3-D printer. There are hundreds of thousands of these 3-D printers deployed globally [95], which are thus readily accessible to most labs. Although early desktop printers were challenging for non-experts, a tuned DIY RepRap like the one used in this study or a commercial self-bed leveling open source 3-D printer (e.g. a Lulzbot [97], Prusa [98], or Ultimaker [99]) can be left unattended after the file has been sent to print. This is similar in operation to the use of a 2-D printer or photocopying machine. The print time is not the labor time of the individual operating the printer as the 3-D printer does not need to be monitored by a user during printing. Thus, although the actual 3-D print time is much longer (approximately 9 hours for the slowest printing part, and 40 hours for all prints done in succession on a single printer), the time that labor is focused only on printing is less than half an hour to set up and clear 10 print jobs. For organizations without ready access to a 3-D printer, it should be pointed out that a low-end 3-D printer can be justified for the fabrication of even this tool alone as shown in Table 3. However, there is also access to 3-D printers at FabLabs [100,101], makerspaces [102], hackerspaces [103], and even public libraries [104] often have 3D printing services available either for free, or for the cost of materials. Nearly all modern universities now have at least basic 3-D printing capabilities somewhere on campus, which are 
Preprint: Nupur Bihari, Smruti Prasad Dash, Karankumar C. Dhankani, Joshua M. Pearce. 3-D printable open source dual axis gimbal system for optoelectronic measurements. Mechatronics 56, 175-187 (2018). DOI:

https://doi.org/10.1016/j.mechatronics.2018.07.005

adequate to replicate the open source gimbal system. For researchers with no access to 3-D printers locally, on demand quasi-local 3-D print services (e.g. MakeXYZ [105]) are available. The costs for a 3-D printing service will be more than the costs of the materials alone, but in general reasonable, as there is a high degree of competition because quotes are available immediately for users in any given area.

Table 3. Comparison of available gimbal systems compared to the open source gimbal system for accuracy, micro step size, repeatability and cost.

\begin{tabular}{|l|l|l|l|l|l|}
\hline System & Accuracy & Micro step size & Repeatability & Cost (US\$) & Source \\
\hline $\begin{array}{l}\text { T-OMG } \\
\text { Series: Miniature } \\
\text { motorized gimbal } \\
\text { optic mounts with } \\
\text { built-in controllers }\end{array}$ & $0.055^{\circ}$ & $0.000115378^{\circ}$ & $<0.007^{\circ}$ & $\$ 1,440$ & {$[106]$} \\
\hline $\begin{array}{l}\text { Picomotor Piezo } \\
\text { Optical Mounts }\end{array}$ & $0.000069^{\circ}$ & $4^{\circ}$ & & & \\
\hline $\begin{array}{l}\text { Stability Picomotor } \\
\text { Piezo Optical Mounts }\end{array}$ & $0.00004^{\circ}$ & $4^{\circ}$ & $.00004^{\circ}$ & $\begin{array}{l}\$ 1,088.00- \\
\$ 2,051.00\end{array}$ & {$[107]$} \\
\hline $\begin{array}{l}\text { Open source gimbal } \\
\text { system }\end{array}$ & $2.827^{\circ}$ & $0.022^{\circ}$ & $0.00004^{\circ}$ & $\begin{array}{l}\$ 1,536.00- \\
\$ 2,123.00\end{array}$ & {$[107]$} \\
\hline
\end{tabular}

Next, purchasing the components is a low-skill task, particularly when the hyperlinks to existing suppliers are provided (see [82]) and still active and purchasing is occurring in the United States (U.S.). The total time for this task would be about $12 \mathrm{~min}$. for anyone with an existing Amazon account and shipping is free for those with Amazon prime. In the future, if these components are no longer available on these hyperlinks then they will need to be sourced from other websites, which would increase the time cost. On the other hand, as this is an open source hardware project, any number of entrepreneurs could begin to offer kits with all the components that could be purchased with a single order [108]. It should also be pointed out that it may be possible to decrease the cost of the device by careful comparison shopping for the components, and/or using existing supplies. Regardless of the exact situation, this subtask can be undertaken by the lowest-cost worker in an organization (e.g., a receptionist employed at a company) and represents a trivial cost.

Lastly, once all of the components are gathered they must be assembled by a moderately skilled worker following the instructions provided in this paper. Having designed the system, the researchers in this study could build the device in about $15 \mathrm{~min}$. To remain conservative, for a novice builder the build time is estimated to be under $30 \mathrm{~min}$.

Thus, the overall cost in labor to source, print, and assemble a 3-D printable open source gimbal system is about $1.25 \mathrm{~h}$. This indicates that it is profitable for an organization to use the 
Preprint: Nupur Bihari, Smruti Prasad Dash, Karankumar C. Dhankani, Joshua M. Pearce. 3-D printable open source dual axis gimbal system for optoelectronic measurements. Mechatronics 56, 175-187 (2018). DOI:

https://doi.org/10.1016/j.mechatronics.2018.07.005

open source version if their labor costs are under $\$ 250 / \mathrm{h}$, even for the least expensive commercial equivalent (or under $\$ 330 / \mathrm{h}$ for the average commercial system).

Finally, a point should be made about the life cycle cost advantages of the open source gimbal system. All of the design files are freely shared and the BOM is known. Thus, regardless of the cause of the failure of the device it can be easily repaired from readily available components (e.g. the user can reprint a broken plastic component or replace a stepper motor). This ease of repair (and even the ability to upgrade) is simply not available for all of the commercial systems, which would often demand the purchasing of a replacement device or a highly skilled and thus expensive repair. Furthermore, the ability to reuse parts from previously completed projects is also demonstrated in the addition of support structures from the open source laboratory sample rotator mixer and shaker [61]. Thus, the value of the open source tool can be considered higher than the commercial functional equivalent, even though the open source tool costs less than $5 \%$ of the cost of the commercial system to build upfront.

In light of the open source nature of this system, which opens up collaborative opportunities for further improvement, the current cost may justify the lower accuracy and higher errors associated with measurements made on this system. The quantified metrics of the system are acceptable for provisional testing and feasibility analyses of thin film transmittances. The system as described is thus adequate for the optical measurements it was designed for, but other researchers will need to carefully assess if the system meets the needs for their experiments as designed, if it needs to be improved, or if a full commercial system is warranted. Since the schematic is openly shared, in the future, upgrades to the microcontroller, motors and drivers can be made to further improve the characteristics. The design as described was optimized for quick print speeds. For this, standard print quality was used with a low level of infill. These parameters as well as the mechanical strength can be improved significantly by printer settings and material selection (e.g. print in polycarbonate) for a more robust system that may have a lower maintenance need.

This system also allows for a variety of custom-made sample holders, which could be designed and printed by a moderately skilled user. While the system used in this study is optimized for optical measurements of TCOs on a $75 \mathrm{~mm}$ x 25mm x $1 \mathrm{~mm}$ glass slide, different sample holders may be designed for up to $50 \mathrm{~mm}$ silicon wafers. The smallest sample holder size is limited by the spot size of the radiation and printing capabilities. The overall cost of the current set up is $1.97 \%$ of the most expensive commercial variant analyzed in this study and $4 \%$ of the least expensive. This saving in initial cost could potentially result in vast improvements.

This system could be expanded to include z-axis rotation as well with no required change in the skillset of the designer.The usability of this system may be expanded to optical alignment systems [109], active response systems [110], and as a mount for cameras in altitude estimation [111]. With minor modifications, this has applications not only in the semiconductor and optics fields but also in robotics, computer vision and surveying.

Both the low cost and the open source nature of the open source gimbal system are important as they provide accessibility to a wider range of users than was available. The potential populations 
Preprint: Nupur Bihari, Smruti Prasad Dash, Karankumar C. Dhankani, Joshua M. Pearce. 3-D printable open source dual axis gimbal system for optoelectronic measurements. Mechatronics 56, 175-187 (2018). DOI:

https://doi.org/10.1016/j.mechatronics.2018.07.005

that will benefit from such a system include optics researchers at universities as well as K-12 teachers and Science, Technology, Engineering and Mathematics (STEM) outreach professionals who are typically in favor of building their own research equipment due to lower costs and easy troubleshooting due to a high degree of familiarity with apparatus. This study is also expected to have a greater impact in developing nations where the need to reduce costs while maintaining adequate technical performance is more significant than in well-funded laboratories [112].

\section{Conclusions}

The process of building a low cost two-axis gimbal system using RepRap 3-D printed parts is described and all non-printed parts are commercially available and inexpensive. The system performed as expected has a unidirectional accuracy of $2.827^{\circ}$, repeatability of $1.585^{\circ}$ and a backlash error of $1.237^{\circ}$. Despite the highest mean squared errors, the open source gimbal system performed adequately while measuring transmission of radiation through glass slides with TCO coatings. This open source system also represents a $96 \%$ cost in savings as compared to the least expensive commercial variant. This study also opens up further opportunities for design improvements to modify the system based on user-specific applications.

Acknowledgements: This work was supported by the MOST lab and Fulbright Finland.

\section{References}

1. Narduzzo, A. and Rossi, A., 2008. Modularity in action: GNU/Linux and free/open source software development model unleashed (No. 020). Department of Computer and Management Sciences, University of Trento, Italy.

2. Meyer, M.H., Seliger, R., 1998. Product Platforms in Software Development. Sloan Management Review; Cambridge 40, 61-74.

3. Allen, E.B., Khoshgoftaar, T.M. and Chen, Y., 2001. Measuring coupling and cohesion of software modules: an information-theory approach. In Software Metrics Symposium, 2001. METRICS 2001. Proceedings. Seventh International (pp. 124-134). IEEE.

4. Laat, P.B. de, 2007b. Governance of open source software: state of the art. J Manage Governance 11, 165-177. doi:10.1007/s10997-007-9022-9

5. Grant, R.M., 1996. Toward a knowledge-based theory of the firm. Strat. Mgmt. J. 17, 109-122. doi:10.1002/smj.4250171110

6. Simon, H.A., 1991. Organizations and Markets. The Journal of Economic Perspectives 5, $25-44$.

7. Taylor, J.B., 1993, December. Discretion versus policy rules in practice. In CarnegieRochester conference series on public policy (Vol. 39, pp. 195-214). North-Holland.

8. Hertel, G., Niedner, S., Herrmann, S., 2003. Motivation of software developers in Open Source projects: an Internet-based survey of contributors to the Linux kernel. Research 
Preprint: Nupur Bihari, Smruti Prasad Dash, Karankumar C. Dhankani, Joshua M. Pearce. 3-D printable open source dual axis gimbal system for optoelectronic measurements. Mechatronics 56, 175-187 (2018). DOI: https://doi.org/10.1016/j.mechatronics.2018.07.005

Policy, Open Source Softwar Development 32, 1159-1177. doi:10.1016/S00487333(03)00047-7

9. Lee, G.K., Cole, R.E., 2003. From a Firm-Based to a Community-Based Model of Knowledge Creation: The Case of the Linux Kernel Development. Organization Science 14, 633-649. doi:10.1287/orsc.14.6.633.24866

10. Kogut, B., Metiu, A., 2001. Open-Source Software Development and Distributed Innovation. Oxf Rev Econ Policy 17, 248-264. doi:10.1093/oxrep/17.2.248

11. Mockus, A., Fielding, R.T., Herbsleb, J., 2000. A case study of open source software development: the Apache server, in: Proceedings of the 2000 International Conference on Software Engineering. ICSE 2000 the New Millennium. Presented at the Proceedings of the 2000 International Conference on Software Engineering. ICSE 2000 the New Millennium, pp. 263-272. doi:10.1145/337180.337209

12. Bagozzi, R.P., Dholakia, U.M., 2006. Open Source Software User Communities: A Study of Participation in Linux User Groups. Management Science 52, 1099-1115. doi:10.1287/mnsc.1060.0545

13. Dempsey, B.J., Weiss, D., Jones, P., Greenberg, J., 1999. A quantitative profile of a community of open source Linux developers. Chapel Hill: School of Information and Library Science, University of North Carolina

14. Hars, A., Ou, S., 2001. Working for free? Motivations of participating in open source projects, in: Proceedings of the 34th Annual Hawaii International Conference on System Sciences. Presented at the Proceedings of the 34th Annual Hawaii International Conference on System Sciences, p. 9 pp.-.doi:10.1109/HICSS.2001.927045

15. Feller, J., Fitzgerald, B., others, 2002. Understanding open source software development. Addison-Wesley London.

16. Bonaccorsi, A., Rossi, C., 2003. Why Open Source software can succeed. Research Policy, Open Source Software Development 32, 1243-1258. doi:10.1016/S00487333(03)00051-9f

17. Crowston, K., Howison, J., 2005. The social structure of free and open source software development. First Monday 10. doi:10.5210/fm.v10i2.1207

18. Tu, Q., 2000. Evolution in open source software: A case study. In Software Maintenance, 2000. Proceedings. International Conference on (pp. 131-142). IEEE.

19. Drumea, A., 2012. Education in development of electronic modules using free and open source software tools. "HIDRAULICA” Magazine of Hydraulics, Pneumatics, Tribology, Ecology, Sensorics, Mechatronics, (3-4), pp.54-60.

20. Sarker, M.O.F., Kim, C. and You, B.J., 2006, July. Development of a network-based realtime robot control system over IEEE 1394: Using open source software platform. In Mechatronics, 2006 IEEE International Conference on (pp. 563-568). IEEE.

21. Xi, X.C., Hong, G.S. and Poo, A.N., 2010. Improving CNC contouring accuracy by integral sliding mode control. Mechatronics, 20(4), pp.442-452.

22. Gibb, A., 2014. Building Open Source Hardware: DIY Manufacturing for Hackers and Makers. Pearson Education. 
Preprint: Nupur Bihari, Smruti Prasad Dash, Karankumar C. Dhankani, Joshua M. Pearce. 3-D printable open source dual axis gimbal system for optoelectronic measurements. Mechatronics 56, 175-187 (2018). DOI: https://doi.org/10.1016/j.mechatronics.2018.07.005

23. Balka, K., Raasch, C., Herstatt, C., 2009. Open source enters the world of atoms: A statistical analysis of open design. First Monday 14. doi:10.5210/fm.v14i11.2670

24. Zhang, L., Slaets, P. and Bruyninckx, H., 2012. An open embedded hardware and software architecture applied to industrial robot control. In Mechatronics and Automation (ICMA), 2012 International Conference on (pp. 1822-1828). IEEE.

25. Banzi, M. and Shiloh, M., 2014. Getting Started with Arduino: The Open Source Electronics Prototyping Platform. Maker Media, Inc.

26. Pearce, J.M., 2012. Building research equipment with free, open-source hardware. Science, 337(6100), pp.1303-1304.

27. Baldwin, C.Y., Clark, K.B., 2000. Design Rules: The power of modularity. MIT Press.

28. Pocero, L., Amaxilatis, D., Mylonas, G., \& Chatzigiannakis, I. (2017). Open source IoT meter devices for smart and energy-efficient school buildings. HardwareX, 1, 54-67.

29. McMunn, M. S. (2017). A time-sorting pitfall trap and temperature datalogger for the sampling of surface-active arthropods. HardwareX, 1, 38-45.

30. Oh, J., Hofer, R., \& Fitch, W. T. (2017). An open source automatic feeder for animal experiments. HardwareX, 1, 13-21.

31. Buechley, L., Eisenberg, M., Catchen, J., Crockett, A., 2008. The LilyPad Arduino: Using Computational Textiles to Investigate Engagement, Aesthetics, and Diversity in Computer Science Education, in: Proceedings of the SIGCHI Conference on Human Factors in Computing Systems, CHI ’08. ACM, New York, NY, USA, pp. 423-432. doi:10.1145/1357054.1357123.

32. Coyle, S., Morris, D., Lau, K.T., Diamond, D., Moyna, N., 2009. Textile-Based Wearable Sensors for Assisting Sports Performance, in: 2009 Sixth International Workshop on Wearable and Implantable Body Sensor Networks. Presented at the 2009 Sixth International Workshop on Wearable and Implantable Body Sensor Networks, pp. 307311. doi:10.1109/BSN.2009.57

33. Sugathan, A., Roy, G.G., Kirthyvijay, G.J., Thomson, J., 2013. Application of arduino based platform for wearable health monitoring system, in: 2013 IEEE 1st International Conference on Condition Assessment Techniques in Electrical Systems (CATCON). Presented at the 2013 IEEE 1st International Conference on Condition Assessment Techniques in Electrical Systems (CATCON), pp. 1-5. doi:10.1109/CATCON.2013.6737464

34. Purusothaman, S.R.R.D., Rajesh, R., Vijayaraghavan, V., Bajaj, K.K., 2014. Design of Arduino-based communication agent for rural Indian microgrids, in: 2014 IEEE Innovative Smart Grid Technologies - Asia (ISGT ASIA). Presented the 2014 IEEE Innovative Smart Grid Technologies - Asia (ISGT ASIA), pp. 630-634. doi:10.1109/ISGT-Asia.2014.6873865

35. Zachariadou, K., Yiasemides, K., Trougkakos, N., 2012. A low-cost computer-controlled Arduino-based educational laboratory system for teaching the fundamentals of photovoltaic cells. Eur. J. Phys. 33,1599. doi:10.1088/0143-0807/33/6/1599 
Preprint: Nupur Bihari, Smruti Prasad Dash, Karankumar C. Dhankani, Joshua M. Pearce. 3-D printable open source dual axis gimbal system for optoelectronic measurements. Mechatronics 56, 175-187 (2018). DOI: https://doi.org/10.1016/j.mechatronics.2018.07.005

36. Kentzer, J., Koch, B., Thiim, M., Jones, R.W. and Villumsen, E., 2011, May. An open source hardware-based mechatronics project: The replicating rapid 3-D printer. In Mechatronics (ICOM), 2011 4th International Conference On (pp. 1-8). IEEE.

37. Baraka, K., Ghobril, M., Malek, S., Kanj, R. and Kayssi, A., 2013, June. Low cost arduino/android-based energy-efficient home automation system with smart task scheduling. In Computational Intelligence, Communication Systems and Networks (CICSyN), 2013 Fifth International Conference on (pp. 296-301). IEEE.

38. Piyare, R., Tazil, M., 2011. Bluetooth based home automation system using cell phone, in: 2011 IEEE 15 $5^{\text {th }}$ International Symposium on Consumer Electronics (ISCE). Presented at the 2011 IEEE $15^{\text {th }}$ International Symposium on Consumer Electronics (ISCE), pp. 192-195. doi:10.1109/ISCE.2011.5973811

39. Kumar, P., Kumar, P., 2013. Arduino based wireless intrusion detection using IR sensor and GSM. International Journal of Computer Science and Mobile Computing 2, 417-424.

40. Pearce, J.M., 2013. Open-Source Lab: How to Build Your Own Hardware and Reduce Research Costs. Elsevier: New York.

41. Ferdoush, S., Li, X., 2014. Wireless Sensor Network System Design Using Raspberry Pi and Arduino for Environmental Monitoring Applications. Procedia Computer Science, The 9th International Conference on Future Networks and Communications (FNC'14)/The 11th International Conference on Mobile Systems and Pervasive Computing (MobiSPC’14)/Affiliated Workshops 34, 103-110. doi:10.1016/j.procs.2014.07.059

42. Méndez, D., Pérez, A.J., Labrador, M.A., Marrón, J.J., 2011. P-Sense: A participatory sensing system for air pollution monitoring and control, in: 2011 IEEE International Conference on Pervasive Computing and Communications Workshops (PERCOM Workshops). Presented at the 2011 IEEE International Conference on Pervasive Computing and Communications Workshops (PERCOM Workshops), pp. 344-347. doi:10.1109/PERCOMW.2011.5766902

43. Lee, S., Jo, J., Kim, Y., Stephen, H., 2014. A Framework for Environmental Monitoring with Arduino-Based Sensors Using Restful Web Service, in: 2014 IEEE International Conference on Services Computing. Presented at the 2014 IEEE International Conference on Services Computing, pp. 275-282. doi:10.1109/SCC.2014.44

44. Gertz, E., Justo, P.D., 2012. Environmental Monitoring with Arduino: Building Simple Devices to Collect Data About the World Around Us. O’Reilly Media, Inc.

45. Busquets, J., Busquets, J.V., Tudela, D., Pérez, F., Busquets-Carbonell, J., Barberá, A., Rodríguez, C., García, A.J., Gilabert, J., 2012. Low-cost AUV based on Arduino open source microcontroller board for oceanographic research applications in a collaborative long term deployment missions and suitable for combining with an USV as autonomous automatic recharging platform, in: Autonomous Underwater Vehicles (AUV), 2012 IEEE/OES. IEEE, pp. 1-10. 
Preprint: Nupur Bihari, Smruti Prasad Dash, Karankumar C. Dhankani, Joshua M. Pearce. 3-D printable open source dual axis gimbal system for optoelectronic measurements. Mechatronics 56, 175-187 (2018). DOI: https://doi.org/10.1016/j.mechatronics.2018.07.005

46. Leeuw, T., Boss, E.S., Wright, D.L., 2013. In situ Measurements of Phytoplankton Fluorescence Using Low Cost Electronics. Sensors 13, 7872-7883. doi:10.3390/s130607872

47. Alkandari, A., alnasheet, M., Alabduljader, Y., Moein, S.M., 2012. Water monitoring system using Wireless Sensor Network (WSN): Case study of Kuwait beaches, in: 2012 Second International Conference on Digital Information Processing and Communications (ICDIPC). Presented at the 2012 Second International Conference on Digital Information Processing and Communications (ICDIPC), pp. 10-15. doi:10.1109/ICDIPC.2012.6257270

48. Bardají, R., Zafra, E., Simon, C., Piera, J., 2014. Comparing water transparency measurements obtained with low-cost citizens science instruments and high-quality oceanographic instruments, in: OCEANS 2014 - TAIPEI. Presented at the OCEANS 2014 - TAIPEI, pp. 1-4. doi:10.1109/OCEANSTAIPEI. 2014.6964550

49. Navajas, G.T. and Prada, S.R., 2014, October. Building your own quadrotor: A mechatronics system design case study. In Engineering Mechatronics and Automation (CIIMA), 2014 III International Congress of (pp. 1-5). IEEE.

50. Abaid, N., Bernhardt, J., Frank, J.A., Kapila, V., Kimani, D. and Porfiri, M., 2013. Controlling a robotic fish with a smart phone. Mechatronics, 23(5), pp.491-496.

51. Jenabi, S.H., Shahri, A.M. and Beyad, M.R., 2016, January. Advanced mechatronics course based on wheeled mobile robots and real-time embedded control experimental setups. In Control, Instrumentation, and Automation (ICCIA), 2016 4th International Conference on (pp. 413-418). IEEE.

52. Grover, R., Krishnan, S., Shoup, T. and Khanbaghi, M., 2014, March. A competitionbased approach for undergraduate mechatronics education using the arduino platform. In Interdisciplinary Engineering Design Education Conference (IEDEC), 2014 4th (pp. 78-83). IEEE.

53. Asato, K., Asato, K., Nagado, T. and Tamaki, S., 2015, November. Development of low cost educational material for learning fundamentals of mechatronics. In Intelligent Informatics and Biomedical Sciences (ICIIBMS), 2015 International Conference on (pp. 454-456). IEEE.

54. Soriano, A., Marin, L., Valles, M., Valera, A. and Albertos, P., 2014. Low Cost Platform for Automatic Control Education Based on Open Hardware. IFAC Proceedings Volumes, 47(3), pp.9044-9050.

55. Jones, R., Haufe, P., Sells, E., Iravani, P., Olliver, V., Palmer, C. and Bowyer, A., 2011. RepRap-the replicating rapid prototyper. Robotica, 29(01), pp.177-191.

56. Rundle, G., 2014. A Revolution in the Making. Simon and Schuster.

57. Gonzalez-Gomez, J., Valero-Gomez, A., Prieto-Moreno, A. and Abderrahim, M., 2012. A new open source 3d-printable mobile robotic platform for education. In Advances in autonomous mini robots (pp. 49-62). Springer Berlin Heidelberg. 
Preprint: Nupur Bihari, Smruti Prasad Dash, Karankumar C. Dhankani, Joshua M. Pearce. 3-D printable open source dual axis gimbal system for optoelectronic measurements. Mechatronics 56, 175-187 (2018). DOI:

https://doi.org/10.1016/j.mechatronics.2018.07.005

58. Irwin, J.L., Pearce, J.M., Anzolone, G. and Oppliger, D.E., 2014, June. The RepRap 3-D printer revolution in STEM education. In 121st ASEE Annual Conference \& Exposition (pp. 15-18).

59. Schelly, C., Anzalone, G., Wijnen, B. and Pearce, J.M., 2015. Open-source 3-D printing technologies for education: Bringing additive manufacturing to the classroom. Journal of Visual Languages \& Computing, 28, pp.226-237.

60. Baden, T., Chagas, A.M., Gage, G., Marzullo, T., Prieto-Godino, L.L. and Euler, T., 2015. Open Labware: 3-D printing your own lab equipment. PLoS Biol, 13(3), p.e1002086.

61. Dhankani, K.C., Pearce, J.M., 2017. Open source laboratory sample rotator mixer and shaker. HardwareX 1, 1-12. doi:10.1016/j.ohx.2016.07.001

62.https://3dprint.nih.gov/

63.https://www.youmagine.com/

64.https://www.myminifactory.com/

65. https://grabcad.com/

66. https://www.thingiverse.com/

67. Wittbrodt, B.T., Glover, A.G., Laureto, J., Anzalone, G.C., Oppliger, D., Irwin, J.L. and Pearce, J.M., 2013. Life-cycle economic analysis of distributed manufacturing with opensource 3-D printers. Mechatronics, 23(6), pp.713-726.

68. Willis, K., Brockmeyer, E., Hudson, S., Poupyrev, I., 2012. Printed Optics: 3D Printing of Embedded Optical Elements for Interactive Devices, in: Proceedings of the 25th Annual ACM Symposium on User Interface Software and Technology, UIST '12. ACM, New York, NY, USA, pp. 589-598. doi:10.1145/2380116.2380190

69. Brockmeyer, E., Poupyrev, I., Hudson, S., 2013. PAPILLON: Designing Curved Display Surfaces with Printed Optics, in: Proceedings of the 26th Annual ACM Symposium on User Interface Software and Technology, UIST '13. ACM, New York, NY, USA, pp. 457462. doi:10.1145/2501988.2502027

70. Bentz, B.Z., Chavan, A.V., Lin, D., Tsai, E.H. and Webb, K.J., 2016. Fabrication and application of heterogeneous printed mouse phantoms for whole animal optical imaging. Applied optics, 55(2), pp.280-287.

71. Zou, L., Koslakiewicz, R., Mahmoud, M., Fahs, M., Liu, R. and Lo, J.F., 2016. Threedimensional printed miniaturized spectral system for collagen fluorescence lifetime measurements. Journal of biomedical optics, 21(7), pp.075001-075001.

72. Sharkey, J.P., Foo, D.C., Kabla, A., Baumberg, J.J. and Bowman, R.W., 2016. A onepiece 3D printed flexure translation stage for open-source microscopy. Review of Scientific Instruments, 87(2), p.025104.

73. Coakley, M. and Hurt, D.E., 2016. 3D Printing in the Laboratory: Maximize Time and Funds with Customized and Open-Source Labware. Journal of Laboratory Automation, 21(4), pp.489-495.

74. Wijnen, B., Petersen, E.E., Hunt, E.J. and Pearce, J.M., 2016. Free and open-source automated 3-D microscope. Journal of Microscopy, 264(2), pp.238-246.

75. Zhang, C., Anzalone, N.C., Faria, R.P. and Pearce, J.M., 2013. Open-source 3D-printable optics equipment. PloS one, 8(3), p.e59840. 
Preprint: Nupur Bihari, Smruti Prasad Dash, Karankumar C. Dhankani, Joshua M. Pearce. 3-D printable open source dual axis gimbal system for optoelectronic measurements. Mechatronics 56, 175-187 (2018). DOI: https://doi.org/10.1016/j.mechatronics.2018.07.005

76. Zhao, J., Green, M.A., 1991. Optimized antireflection coatings for high-efficiency silicon solar cells. IEEE Transactions on Electron Devices 38, 1925-1934. doi:10.1109/16.119035

77. Zhao, J., Wang, A., Altermatt, P. and Green, M.A., 1995. Twenty-four percent efficient silicon solar cells with double layer antireflection coatings and reduced resistance loss. Applied Physics Letters, 66(26), pp.3636-3638.

78. Parretta, A., Sarno, A., Tortora, P., Yakubu, H., Maddalena, P., Zhao, J. and Wang, A., 1999. Angle-dependent reflectance measurements on photovoltaic materials and solar cells. Optics Communications, 172(1-6), pp.139-151.

79. Pfaff, G., Reynders, P., 1999. Angle-Dependent Optical Effects Deriving from Submicron Structures of Films and Pigments. Chem. Rev. 99, 1963-1982. doi:10.1021/cr970075u

80. Tsuji, J., 1927-, 1995. Palladium reagents and catalysts. Wiley \& Sons.

81. Oberloier, S. and Pearce, J.M. General Design Procedure for Free and Open-Source Hardware for Scientific Equipment. Designs 2018, 2(1), 2; doi:10.3390/designs2010002

82. Open Source Dual Axis Gimbal System https://osf.io/6nse3/ (accessed 12.8.2017)

83. FreeCAD https://www.freecadweb.org/ (accessed 5.2.2017).

84.https://www.lulzbot.com/store/filament

85. Anzalone, G.C., Wijnen, B. and Pearce, J.M., 2015. Multi-material additive and subtractive prosumer digital fabrication with a free and open-source convertible delta RepRap 3-D printer. Rapid Prototyping Journal, 21(5), pp.506-519.

86. Wijnen, B., Anzalone, G.C., Haselhuhn, A.S., Sanders, P.G., Pearce, J.M., 2016. Free and Open-source Control Software for 3-D Motion and Processing. Journal of Open Research Software 4. doi:10.5334/jors.78

87. Arduino. Arduino IDE. https://www.arduino.cc/en/Main/Software (accessed 5.2.2017).

88. Leenhouts, A.C., 1997. Step motor system design handbook. Litchfield Engineering.

89. Rogers, J.R. and Craig, K., 2005. On-hardware optimization of stepper-motor system dynamics. Mechatronics, 15(3), pp.291-316.

90. Muñiz, C., Levi, R., Benkrid, M., Rodríguez, F.B. and Varona, P., 2008. Real-time control of stepper motors for mechano-sensory stimulation. Journal of Neuroscience Methods, 172(1), pp.105-111.

91. Banihani, S., Al-Widyan, K., Al-Jarrah, A. and Ababneh, M., 2013. A genetic algorithm based lookup table approach for optimal stepping sequence of open-loop stepper motor systems. Journal of Control Theory and Applications, 11(1), pp.35-41.

92. Righettini, P., Strada, R., Oldani, A.C. and Ginammi, A., 2012. An experimental investigation on the dynamic behavior of step motor drives. Journal of Mechanics Engineering and Automation, 2(7), pp.431-440.

93. Baluta, G., 2007, July. Microstepping mode for stepper motor control. In Signals, Circuits and Systems, 2007. ISSCS 2007. International Symposium on (Vol. 2, pp. 1-4). IEEE.

94. Bailey, M.; Grieco, J.; Speights, A.; Weiss, R.G. 3D printing in the classroom and laboratory. J. Comput. Sci. Coll. 2015, 31, 183-184.

95. Wohler, T. (2016). Wohlers report 2016. Wohlers Associates, Inc. 
Preprint: Nupur Bihari, Smruti Prasad Dash, Karankumar C. Dhankani, Joshua M. Pearce. 3-D printable open source dual axis gimbal system for optoelectronic measurements. Mechatronics 56, 175-187 (2018). DOI:

https://doi.org/10.1016/j.mechatronics.2018.07.005

96. Petersn, E. E., \& Pearce, J. (2017). Emergence of Home Manufacturing in the Developed World: Return on Investment for Open-Source 3-D Printers. Technologies, 5(1), 7. doi:10.3390/technologies5010007

97. https://www.lulzbot.com/

98.https://www.prusa3d.com/

99. https://ultimaker.com/

100. Stacey, M. The FAB LAB network: A global platform for digital invention, education and entrepreneurship. Innovations 2014, 9, 221-238.

101. Fab Foundation. Fab Labs. Available online: http://www.fabfoundation.org/fablabs/ (accessed on 31 October 2017).

102. The Maker Map. Available online: http://themakermap.com/ (accessed on 31 October 2017).

103. Hackespaces. Available online: https://wiki.hackerspaces.org/ (accessed on 31 October 2017).

104. Mooreield-Lang, H. 3-D printing in your libraries and classrooms. Knowl. Quest 2014, 43, 70-73.

105. MakeXYZ Available online: https://www.makexyz.com/ (accessed on 31 October 2017).

106. ZaberTechnologies https://www.zaber.com/products/product detail.php?detail=T$\underline{\mathrm{OMG}}$

107. Newport Photonics Solutions https://www.newport.com/f/picomotor-piezomirror-mounts

108. Pearce, J. M. (2017). Emerging Business Models for Open Source Hardware. Journal of Open Hardware, 1(1). Doi: http://doi.org/10.5334/joh.4

109. Burge, J.H., Su, P., Zhao, C. and Zobrist, T., 2007, September. Use of a commercial laser tracker for optical alignment. In Proc. SPIE (Vol. 6676, p. 66760E).

110. Wilson, G.W., 1975, August. Double gimbal control moment gyroscope-gimbal control loop synthesis. In AIAA, Guidance and Control Conference.

111. Zhang, R. and Liu, H.H., 2011, June. Vision-based relative altitude estimation of small unmanned aerial vehicles in target localization. In American Control Conference (ACC), 2011 (pp. 4622-4627). IEEE.

112. J. Gwamuri, and Pearce, 2017. Open source 3D printers: an appropriate technology for building low cost optics labs for the developing communities", Proc. SPIE 10452, 14th Conference on Education and Training in Optics and Photonics: ETOP 2017, 104522S (16 August 2017); doi: 10.1117/12.2269852

\section{Biographies}

Nupur Bihari received her MS in Electrical Engineering from Michigan Technological University in 2015. She is currently a doctoral student in Materials Science and Engineering, Michigan Technological University. Her research interests include design and fabrication of nano and microscale level devices and optoelectronic phenomena. 
Preprint: Nupur Bihari, Smruti Prasad Dash, Karankumar C. Dhankani, Joshua M. Pearce. 3-D printable open source dual axis gimbal system for optoelectronic measurements. Mechatronics 56, 175-187 (2018). DOI: https://doi.org/10.1016/j.mechatronics.2018.07.005

Smruti Prasad Dash received his B.Tech in Electronics and Electrical Engineering from KIIT University (India) in 2013. He is currently a Master's student in Electrical and Computer Engineering, Michigan Technological University. His research interests include design and implementation of vehicle communication systems using open source software and hardware.

Karankumar Dhankani received his Master's in Mechanical Engineering from Michigan Technological University in 2017. He currently works as a Systems Engineer at Bosch Engineering in the Silicon Valley with a focus on Electric and Hybrid Vehicle Systems and Controls design. He is also interested and has worked on various 3-D printed laboratory equipment design during his Master's degree.

Joshua M. Pearce is a Professor cross-appointed in the Department of Materials Science \& Engineering and in the Department of Electrical \& Computer Engineering at the Michigan Technological University where he runs the Open Sustainability Technology Research Group. He is the editor-in-chief of HardwareX, a journal dedicated to open source scientific hardware and his is the author of the Open-Source Lab: How to Build Your Own Hardware and Reduce Research Costs. 